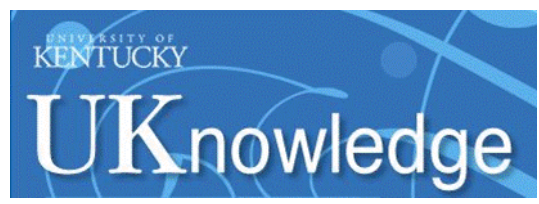

University of Kentucky UKnowledge

9-15-2019

\title{
Imatinib Mesylate Effects on Zebrafish Reproductive Success: Gonadal Development, Gamete Quality, Fertility, Embryo-Larvae Viability and Development, and Related Genes
}

Nader Ahmadi

Urmia University, Iran

Seyed-Mohammadreza Samaee

Urmia University, Iran

Robert A. Yokel

University of Kentucky, ryokel@email.uky.edu

Aliasghar Tehrani

Urmia University, Iran

Right click to open a feedback form in a new tab to let us know how this document benefits you. Follow this and additional works at: https://uknowledge.uky.edu/ps_facpub

Part of the Food Science Commons, and the Pharmacy and Pharmaceutical Sciences Commons 


\section{Imatinib Mesylate Effects on Zebrafish Reproductive Success: Gonadal Development, Gamete Quality, Fertility, Embryo-Larvae Viability and Development, and Related Genes}

Digital Object Identifier (DOI)

https://doi.org/10.1016/j.taap.2019.114645

Notes/Citation Information

Published in Toxicology and Applied Pharmacology, v. 379, 114645.

(c) 2019 Elsevier Inc.

(c) 2019. This manuscript version is made available under the CC-BY-NC-ND 4.0 license https://creativecommons.org/licenses/by-nc-nd/4.0/.

The document available for download is the authors' post-peer-review final draft of the article. 
1 Imatinib mesylate effects on zebrafish reproductive success: gonadal development,

2 gamete quality, fertility, embryo-larvae viability and development, and related genes

4 Nader Ahmadi ${ }^{1}$, Seyed-Mohammadreza Samaee ${ }^{1 *}$, Robert A. Yokel $^{2}$, Aliasghar Tehrani $^{3}$

5

$6{ }^{1}$ Aquatic Lab, Department of Food Hygiene and Quality Control, Faculty of Veterinary Medicine, Urmia University, Urmia 165, Iran

${ }^{2}$ Department of Pharmaceutical Sciences, University of Kentucky, Lexington, KY, USA

${ }^{3}$ Department of Pathobiology, Faculty of Veterinary Medicine, Urmia University, Urmia 165, Iran

*Author of correspondence: Seyed-Mohammadreza Samaee; Tel: +98-044-32770508; Email: seyedmohammadreza.samaee@gmail.com \& mohammadreza_samaee@yahoo.com; ORCID: 0000-0002-9104-0299.

Running title: Imatinib-induced reproductive defects in zebrafish

Abstract - Imatinib (IM) is a tyrosine kinase (TK) inhibitor (TKI) used to treat chronic myeloid leukemia. Clinical case reports and a few laboratory mammal studies provide inconclusive evidence about its deleterious effects on reproduction. The aim of the current study was to evaluate the potential of zebrafish to characterize IM-induced effects on reproduction and clarify IM effects on reproductive success. To this end, we exposed adult zebrafish to four concentrations of IM for 30 days followed by a 30-day depuration period.

24 IM exposure caused a concentration-dependent, irreversible, suppression of folliculogenesis, reversible decrease in sperm density and motility, decreased fecundity and fertility, but no 
significant change in atretic follicle abundance. We also observed IM-induced premature hatching, but no significant change in embryo-larvae survivability. However, we found significant IM-induced morphometric malformations. IM decreased expression of vegfaa and igf $2 a$ (two reproductive-, angiogenic-, and growth-related genes) in testes and ovaries. The results demonstrate IM can induce significant changes in critical reproductive endpoints and zebrafish as a suitable model organism to show effects of IM on reproduction. The findings suggest that TKI effects on reproductive success should be considered.

Keywords: igf $2 a$, Imatinib, Reproduction, vegfaa, Zebrafish

\section{Introduction}

Imatinib mesylate (IM) is a tyrosine kinase (TK) inhibitor (TKI) (Loren et al., 2013) developed in the mid-1990s (Heinrich et al., 2000). It was first used in 1998 to treat chronic myeloid leukemia (CML) (Mughal and Schrieber, 2010) and has since become a standard therapeutic agent against CML (Ault et al., 2006). IM is the first in a family of highly effective, minimally toxic, agents widely used to treat CML (Zamah et al., 2011).

IM is not specific for Bcr-Abl (a gene often found in CML patients that codes for a TK protein) and binds to at least 25 kinases with varying affinities (Karaman et al., 2008), e.g. KIT, platelet-derived growth factor receptor (PDGFR), abelson-related gene (ARG), and Colony-stimulating factor-1 receptor (c-FMS). These proteins are known to have functions that may play a role in gonadal development, embryo implantation, and fetal development

47 (Tybulewicz et al., 1991; Mauduit et al., 1999; Soriano, 1994, 1997; Hoch and Soriano, 2003). Proteomic analysis of IM-treated human ovarian cancer cells by Patel et al. (2008) showed that exposure of ovarian cells to IM produces complex intracellular changes. 
In early clinical case reports exposure to IM was associated with human ovary deficiencies, e.g. a greatly diminished follicle count (Christopoulos et al., 2008), a severely compromised ovarian response to gonadotropin stimulation, and compromised ovarian hormone production and oocyte recovery (Zamah et al., 2011). Results showed decreased numbers of primary follicles and developed Graafian follicles in rats (Yaghmaei et al., 2009b), increased number of pyknotic bodies in mice (Kerr et al., 2012), and increased apoptosis rate in human oocytes (Bildik et al., 2016).

In contrast, there are human clinical case reports, e.g. Malozowski et al. (2008) and reviewed in Hensley and Ford (2003) as well as studies with laboratory animals (Schultheis et al., 2012), in which IM exposure was not correlated with gonadal defect. There are also controversial clinical case reports on IM congenital effects. Some were reviewed by Hensley and Ford (2003), Ali et al. (2006), and Apperley (2009). The above reports provide inconclusive evidence about deleterious effects of IM on reproduction. There is variation among the studies concerning species, age, maturation status, gender, and exposure regimen (e.g. dose, and exposure duration) that most likely contribute to the varying reported observations. Christopoulos et al. (2008) suggested that awareness of the potential for reproductive toxicity will enable physicians to offer patients appropriate counseling and to consider strategies to preserve fertility before prescribing IM chemotherapy. 2003) in a variety of biomedical research fields (e.g., toxicology, drug discovery, and 71 fertility) (Hoo et al., 2016). The use of zebrafish is consistent with the '3Rs' (reduce, refine and replace) approach of animal use for scientific purposes, potentially replacing animals such as mammals with vertebrates that are considered lower on the phylogenetic scale (The Guide, 2011). 
The aims of this study were to analyze adverse effects of IM on 1) zebrafish ovarian

follicle development, histopathology, and fecundity, 2) sperm density and motility; 3)

viability parameters (fertility, embryo hatchability, and embryo-larvae survivability), 4) larvae morphologic and morphometric malformations, 5) the dose-response of IM-induced reproductive symptoms and their potential reversibility, and 6) the expression of vascular end othelial growth factor Aa [vegfaa $]$ and insulin-like growth factor $2 \mathrm{a}[$ igf $2 a]$ ).

Gonadal development is a complicated process in reproduction in which various genes, biochemical and signaling pathways, and hormonal axes (endocrine, paracrine, and autocrine) are involved. Therefore, selection of specific genes that might explain IM-induced changes in the current study aims was an important challenge. Vegfaa and igf $2 a$ (as angiogenic-, reproductive- and growth-related genes) were selected. Inhibitory effects of IM on vegf (Legros et al., 2004; Raimondi et al, 2014) and igf2 (Pink et al., 2005; Belinsky et al., 2008; de Waal, 2009) have been reported.

\section{Materials and methods}

2.1. Fish culture

Wild-type zebrafish (6 months) were purchased from a local supplier in the North of Iran. The fish have been raised through multiple generations within our facility. Care was taken to select zebrafish with continuously high egg production (King Heiden et al., 2006) and fertilization rate (Braunbeck and Lammer, 2006). For fish housing and maintenance see Samaee et al. (2015). Zebrafish were used and cared for in accordance with standard protocols and guides (Westerfield, 2007; Guide for the Care and Use of Laboratory Animals, 8th edition, 2011). 
IM (Gleevec ${ }^{\circledR} ; 100$ mg/tablet) was obtained from Osvah Pharmaceutical Co. (Tehran,

102 Iran). Two tablets were ground using a mortar and pestle and the resulting powder was added 103 to $500 \mathrm{~mL}$ of $2.5 \% \mathrm{NaCl}$ [Merck] solution yielding $0.4 \mathrm{mg} \mathrm{mL}^{-1} \mathrm{IM}$. The suspension was 104 sonicated (power: 70\%; duty: 50\%) for $30 \mathrm{~min}$ (resulting in a homogeneous cloudy suspension). The IM dose was based on the average human dose of $600 \mathrm{mg} / \mathrm{day}$ to control CML (Ohyashiki et al., 2002; James et al., 2003; Prabhash et al., 2005; Christopoulos et al. 2008; Pye et al., 2008; Zamah et al., 2011; Bay et al., 2013), equal to $8 \mathrm{mg}$ per $\mathrm{kg}$ in a human of $75 \mathrm{~kg}$. Fifty $\mathrm{mL}$ IM-BSN suspension $\left(0.4 \mathrm{mg} \mathrm{IM} \mathrm{mL} \mathrm{IM}^{-1}\right.$ [see section "2.5”]) was added to $1950 \mathrm{~mL}$ tank water (see section "2.6") providing fish with a nominal concentration of $10 \mu \mathrm{g}$

$110 \quad \mathrm{IM} \mathrm{mL}^{-1}$.

To ascertain the effects of IM tablet excipients a mix of all the excipients minus the active substance was obtained from Osvah Pharmaceutical Co. Zebrafish were exposed to the excipients in 3 replicates of 10 zebrafish. Endpoints such as the abundance of follicular

114 stages, fecundity, and sperm density and motility were considered to evaluate the biological effects of the excipients. BSN were prepared using the cyst of Artemia franciscana, strain VC, obtained from

119 Can Tho University. The cysts were cultured, hatched overnight, harvested, cleaned, and 120 resuspended as described (Varga, 2011). The total number of BSN in $500 \mathrm{~mL}$ cleaned hatching mixture averaged 94,000. 
A determined number of harvested BSNs were washed in a $100 \mathrm{~mL}$ glass cylinder with $2.5 \%$ salt water, adjusted to $100 \mathrm{~mL}$ with $2.5 \%$ salt water, and the "BSN suspension" 128 stored at $4{ }^{\circ} \mathrm{C}$ with moderate aeration until use.

\subsection{Preparation of "IM-BSN suspension"}

A determined number of harvested BSNs were washed in a $500 \mathrm{~mL}$ glass cylinder with $0.4 \mathrm{mg} \mathrm{mL}-1$ "IM suspension" (see section 2.2), adjusted with "IM suspension" to 500 $\mathrm{mL}$, and the "IM-BSN suspension" moderately and continuously aerated at $28{ }^{\circ} \mathrm{C}$ for less than 1 hour.

The Artemia nauplii used to prepare the IM-BSN suspension were newly hatched that grow on their yolk sac, don't externally feed, and therefore don't take up IM (Van Stappen, 1996), obviating drug metabolism. BSN is a live attractive food for zebrafish. When zebrafish feed on BSN they also ingest the IM suspension. This approach differs from most adult zebrafish drug delivery studies that used direct addition to water (e.g. Maley et al., 2013;

140 Samaee, 2015; Dr. Kiranam Chatti, University of Hyderabad, India [2018], personal communication). Zebrafish were housed in $5 \mathrm{~L}$ mouse Plexiglas cages (Razirad Co, Iran) Samaee et al. (2015). Treatment groups were defined by the frequency of zebrafish feeding with "IM-BSN suspension" and "BSN suspension" for 1 month as follows: on). "IM-1": received a single (1 h after light on) IM-BSN feeding, and 2 regular BSN

149 feedings. "IM-2": received 2 IM-BSN feedings and 1 BSN feeding. "IM-3": received 3 IM- 
150 BSN feedings per day. Each treatment was performed in 3 replicates (with a total of 20

151 zebrafish per replicate).

152 For feedings, the tank filter unit was switched off and some tank water discarded so

153 that $1950 \mathrm{~mL}$ water remained per tank. Fifty $\mathrm{mL}$ of BSN suspension was added (with or

154 without IM). We allowed fish $1 \mathrm{~h}$ (Maley et al., 2013) to consume nauplii, thereafter the tank 155 water was completely changed.

156 IM-induced reproductive endpoint changes were evaluated at two time points: 1) at

157 the end of the IM exposure period, and 2) after 1 month of IM depuration (to assess recovery

158 from IM exposure effects).

2.7. Validation of IM presence in zebrafish tissue

IM-treated fish brains were collected and extracted according to Zhang et al. (2016).

162 Analyses were performed with Waters Alliance 2695 HPLC-Micromass Quattro micro API

163 Mass Spectrometer. LC conditions - mobile phase: $\mathrm{MeOH}+0.1 \%$ Formic Acid and $\mathrm{H}_{2} \mathrm{O}$,

164 column: Atlantis T3-C18 $3 \mu, 2.1 \times 100 \mathrm{~mm}$, column temperature: $30{ }^{\circ} \mathrm{C}$, flow rate: 0.2

$165 \mathrm{~mL} / \mathrm{min}$, and injection volume: $10 \mu \mathrm{L}$. MASS conditions - mode: ESI+, cone Volt: $45 \mathrm{~V}$,

166 capillary Volt: $3 \mathrm{kV}$, extractor: $3 \mathrm{~V}$, RF lens: $0.2 \mathrm{~V}$, collision Energy: $35 \mathrm{eV}$, gas nebulizer:

167 N2 (grade 5), flow gas: $200 \mathrm{~L} / \mathrm{h}$, source temperature: $150{ }^{\circ} \mathrm{C}$, and desolvation temperature: $168350{ }^{\circ} \mathrm{C}$.

170 2.8. Ovarian histology and morphology

Fish were collected after one month of IM exposure and 1 month after IM treatment

172 was stopped. At least six females (King Heiden et al., 2006) from each treatment and control

173 group were fasted (for $24 \mathrm{~h}$ ) then euthanized (Gupta and Mullins, 2010). The fish were

174 decapitated, tails removed, an incision made along their ventral surface, and fixed in $10 \%$ 
formaldehyde (Samaee et al., 2009). Fixed specimens were decalcified by placing them in a

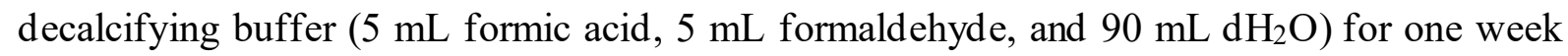
at room temperature. Specimens were dehydrated in a graded series of ethanol, cleared in xylene, and embedded in paraffin. For each specimen, 4-6 distinct sagittal sections at $5 \mu \mathrm{m}$ (taken every $20 \mu \mathrm{m}$ ) from the same region, were transferred onto microscopy slides, stained with hematoxylin and eosin, and cover slipped. Sectioning was standardized according to the relative position of the organ of interest to other structures (Fig. 1b). Sections were examined under a light microscope (C82612, Olympus, Japan) equipped with a digital camera (CMEX DC. 1300 , Netherlands) at $100 \times$ and $400 \times$ magnification. Ovarian follicles were counted and assigned their appropriate gametogenic stage (Fig. 2), based on morphological characteristics as defined by Selman et al. (1993) and Silva et al. (2012). The relative number of follicles at each of the five gametogenic stages/total follicles counted $\times 100$ was calculated (= frequency), based on more than 100 follicles in each ovary (Wang et al., 2011). Images were recorded at 100× and 400× magnification Ovarian follicle diameter was determined on digital photomicrographs using Image Focus (V. 13, Euromex Microscopen b.v., 2005-2006). For each specimen and each follicular stage, we determined the diameter of 10-12 follicles. The identification of atretic follicles and determination of their atresia level (the degeneration of ovarian follicles that do not ovulate), was performed according to Miranda et al. (1999) after discussing with several fish histopathologists.

\subsection{Sperm analysis}

Fish were fasted for $24 \mathrm{~h}$ (Kinkel et al., 2010), anesthetized with cloves (see Grush et al., 2004; half teaspoon of blended dried flowering clove buds, Eugenia caryophyllata, in 250 $\mathrm{mL}$ of system water for $\sim 1 \mathrm{~min}$ ), euthanized, rinsed in fresh water, blotted, weighed (Yang et al., 2007), and immersed in Hank's balanced salt solution (HBSS) (Hagedorn and Carter, 
2011) (in a ratio of 1:50 [mass:volume]) (Dr. Huiping Yang, LSU AgCenter, personal

201 communication). The testes were minced in HBSS (Ingermann et al., 2011) with fine

202 scissors. Testes pieces were gently aspirated into and ejected from an Eppendorf pipette $>20$

203 times to disrupt the tissue and to release mature sperm cells. Large testes fragments were

204 removed with fine forceps, or by a $30 \mathrm{~s}$ spin to isolate heavy tissue fragments from the 205 supernatant suspension (Dr. Qiaoxiang Dong, Institute of Watershed Science and

206 Environmental Ecology, China, personal communication). The resulting suspension

207 containing sperm can be held on ice for $\leq 2 \mathrm{~h}$ (Westerfield, 2000; Hagedorn and Carter, 208 2011).

Sperm density was determined using a hemocytometer. A bright field microscope

210 (Eclipse E600, Nikon, Japan) equipped with a digital camera (Cyber-shot DSC-W130 8.1MP

211 Digital Camera with 4x Optical Zoom with Super Steady Shot, Sony, Japan) was used to

212 record sperm motility. The recordings were analyzed using EDIUS 6 and the percentage of 213 motile sperm within 5, 10, 15, 20, 25, and $30 \mathrm{~s}$ after activation, start of sperm movement after 214 adding water, (denoted spa [seconds post activation]) determined.

2.10. Breeding, embryo collection, and fecundity and fertility determination

Fish breeding, embryo collection and culture, determination of fecundity, 218 embryo/larvae viability parameters (fertilization rate [FR], hatching rate [HR], and 219 survivability rate [SR]), and recording of morphometric characteristics (MC) were carried out 220 according to Samaee et al. (2019). For the breeding trials, 16 zebrafish (8 males and 8 221 females) were taken from the treated (IM-3) and 16 from the untreated (IM-0) groups (Fig. 222 1c-f). To further investigate the effects of IM in both sexes, male and female replacement experiments were conducted. For the male replacement trial eight untreated males were 
housed with IM-3 treated females [Fig. 1e]). For the female replacement trials, eight untreated females were placed with IM-3 treated males [Fig. 1f]).

2.11. Gene expression analysis

Ovary/testis pieces were snap frozen in liquid nitrogen and stored at $-80{ }^{\circ} \mathrm{C}$ until use.

Six specimens from each treatment group were used for gene expression analysis. Total RNA

was extracted using a Bio $\mathrm{FACT}^{\mathrm{TM}} \mathrm{Kit}$ (RP101- 050, Daejeo, Korea) following the manufacturer's instructions, eluted in $20 \mu \mathrm{L}$ RNase-free water, its quality/quantity determined by spectrometry (NanoDrop-Thermo 2000C; Thermo Fisher Scientific, Wilmington, DE, USA), then stored at $-80{ }^{\circ} \mathrm{C}$. Total RNA (10 ng) was reverse transcribed into cDNA using a BioFACT ${ }^{\mathrm{TM}} \mathrm{Kit}$ (BR441-096, Daejeo, Korea) in a $20 \mu \mathrm{L}$ reaction volume by a thermal cycler (model, PEQLAB, Germany), cDNA quantity evaluated by spectrometry, and stored at $-20^{\circ} \mathrm{C}$.

Two target genes (vegfaa and $i g f 2 a$ ) and a housekeeping genes (glyceraldehyde-3phosphate dehydrogenase [gapdh]), as internal standards for the target genes, were used for gene expression analysis. The primers were designed with Primer Express Software (Applied Biosystems) using identical parameters to generate amplicons of similar size. The primers were synthesized by Metabion International AG (Germany).

Quantitative real-time PCR was performed using the StepOne Plus ${ }^{\mathrm{TM}}$ system (Applied

243 Biosystems, Foster City, CA, USA). Each reaction contained $0.5 \mu \mathrm{L}$ diluted cDNA, $0.05 \mu \mathrm{L}$ 244 forward $(10 \mu \mathrm{M})$ and $0.05 \mu \mathrm{L}$ reverse $(10 \mu \mathrm{M})$ primers, and $10 \mu \mathrm{L}$ SYBR Green PCR Master 245 Mix to a final volume of $20 \mu \mathrm{L}$. Amplification followed the PCR cycle condition: $95{ }^{\circ} \mathrm{C}$ for $24610 \mathrm{~min}$, followed by 40 cycles of $15 \mathrm{~s}$ at $95^{\circ} \mathrm{C}$ and $1 \mathrm{~min}$ at $61{ }^{\circ} \mathrm{C}$. Each treatment was 247 analyzed in triplicate (biological replicates) and each sample in triplicate (methodological 248 replicates). A non-template control was performed to ensure that only one PCR product 
amplified and the stock solutions were not contaminated. Cycle conditions and amounts of templates were optimized for each primer set in pilot experiments to ensure that amplification was terminated within the linear phase.

A melting curve was also performed to ensure the specificity of PCR amplification. The melt curve protocol was $15 \mathrm{~s}$ at $95{ }^{\circ} \mathrm{C}$ once and then $10 \mathrm{~s}$ each at $0.3{ }^{\circ} \mathrm{C}$ increments between $60{ }^{\circ} \mathrm{C}$ for $1 \mathrm{~min}$ and $95{ }^{\circ} \mathrm{C}$ for $10 \mathrm{~min}$. Data collection was enabled at each increment of the melt curve. The amplification efficiency, specificity of primers, and amount of cDNA/sample were tested by the standard curve method. Primer pairs were deemed to be acceptable for analysis if they generated standard curves with an $r^{2}$ value above 0.98 , there was consistency among replicates and the primer amplification efficiency was $85-110 \%$.

RNA expression levels are presented as cycle threshold values. The relative expression of genes was calculated by the $2^{-\Delta \Delta C T}$ method (Livak and Schmittgen, 2001) using gapdh. The gapdh did not change among different treatments in any of the experiments. The expression levels of the vegfaa and igf $2 a$ were evaluated relative to gapdh. IM-3 treated fish igf $2 a$ and vegfaa gonad expression level was evaluated relative to untreated fish.

\subsection{Statistical analysis}

Values are reported as mean \pm S.D. Differences among treatment groups were evaluated by one-way analysis of variance followed by Duncan's multiple range test (posthoc) for all endpoints. A p-value of 0.05 was used to set statistical significance levels. Simple regression models were formulated between endpoint magnitudes and the IM exposure frequency to identify concentration-dependent IM-related effects. The levels of significance

$271(\leq 0.002$ [for gonadal parameters] and $p \leq 0.003$ [for morphometric ratios]) for the regression analyses were selected after applying the Bonferroni's adjustment to minimize the chance of 
type I statistical error. All analyses were performed using IBM SPSS (version 20; SPSS Inc.,

274 Chicago, IL, USA), and Excel 2010 (Microsoft Corporation, Redmond, WA, USA).

\section{Results}

277 3.1. Effects of IM tablet excipients on reproductive endpoints

No significant difference was observed between tablet excipient-treated zebrafish (e.g. abundance of follicular stages [e.g. PN; $11.6 \pm 2.0 \%$ ], fecundity $[160.8 \pm 23.1]$, sperm density $\left[4.2713 \times 10^{8} \pm 7.29971969 \times 10^{7}\right.$ per $\mathrm{mL}$ ], and sperm motility [e.g. 5 spa; $77.4 \pm$ $10.3 \%$ ]) and controls (e.g. abundance of follicle stages [e.g. PN; $10.6 \pm 1.4 \%$ ], fecundity $[154.8 \pm 16.4]$, sperm density $\left[4.490750000 \times 10^{8} \pm 6.03184000 \times 10^{7}\right.$ per $\left.\mathrm{mL}\right]$, and sperm motility [e.g. 5 spa; $80.1 \pm 4.0 \%$ ]) concerning the evaluated reproductive endpoints in the current study.

3.2. Presence of IM in tissue

Zebrafish brain IM was $0.08 \pm 0.02 \mathrm{ng} \mathrm{mg}^{-1}$. An IM plasma level of $>0.5 \mu \mathrm{g} \mathrm{mL}^{-1}$ $288\left(0.5 \mathrm{ng} \mathrm{mg}^{-1}\right)$ is needed for tyrosine kinase inhibition in vitro (Peng et al., 2005), > 1,000 $\mathrm{ng}$ $\mathrm{mL}^{-1}\left(1 \mathrm{ng} \mathrm{mg}^{-1}\right)$ to control GIST and CML (Eechoute et al., 2011), and $0.25 \mu \mathrm{M}$ to achieve $50 \%$ inhibition of cellular Bcr/Abl-related tyrosine phosphorylation (Wolff et al., 2003). IM crosses an intact blood-brain barrier poorly (Holdhoff et al., 2010). In the study of Wolff et al. (2003) mice received $150 \mathrm{mg} \mathrm{kg}{ }^{-1} \mathrm{IM}$ daily orally. Plasma IM was $6958 \mathrm{ng} \mathrm{mL} \mathrm{m}^{-1}, 155$ times higher than in the cerebral spinal fluid (CSF) (45 ng mL-1). In Azanza et al. (2018) the IM concentration of CSF was 74 times lower than in the plasma. Therefore, related to the brain IM concentration in the current study the IM level in zebrafish plasma was probably at a clinically-relevant level. 
300 follicles at the PN stage than controls (Fig. 3a), but significantly fewer follicles at eCA,

$301 \mathrm{mCA}, \mathrm{V}$, and $\mathrm{M}$ stages (Fig. $3 \mathrm{~b}$ to e). The number of ovarian follicles at the PN stage [Fig.

302 4a] positively correlated and at the eCA, mCA, V, and $\mathrm{M}$ stages [Fig. 4b to e] with the daily

303 IM exposure frequency.

304 We only found a statistically significant difference between IM-treated fish at the end

305 of IM exposure and the depuration period regarding the proportion of follicles at the mCA 306 stage [Fig. 5c]. At the end of depuration there were non-significant trends toward fewer

307 follicles at eCA and V (Fig. 5b and d), and more follicles at PN, mCA, and M (Fig. 5a, c and 308 e) stages.

\subsection{Follicle diameter}

IM-1, 2, and 3 treated zebrafish ovary follicle diameters at PN, eCA, mCA, V, and M (Fig. $3 \mathrm{f}$ to $\mathrm{j}$ ) stages were consistently smaller compared to controls (IM-0), in some cases significantly. We found a significant, negative linear relationship between the diameter of follicles at the M stage and the frequency of IM exposure (Fig. 4j). Although a negative linear relationship was also observed for the other follicular stages (PN, eCA, mCA, and V [Fig. 4f to i]), the correlations were not statistically significant.

There were no significant differences between the two time-points regarding the 318 diameter of follicles at gametogenic stages (eCA, mCA, V, and $\mathrm{M}$ [Fig. $5 \mathrm{~g}$ to j]). After the depuration period, treated zebrafish had significantly smaller PN (Fig. 5f), non-significantly smaller eCA, mCA, and V (Fig. 5g to i), and larger M (Fig. 5j) ovarian follicles. 
A significant decrease in fecundity was observed in IM-treated $(108 \pm 28)$ zebrafish compared to untreated specimens (control; IM-0, $171 \pm 55)$. The IM-induced decrease in 326 female fecundity did not recover after the 1-month drug depuration period $(104 \pm 19)$.

3.6. Sperm density and motility

The highest and lowest sperm densities were observed in IM-0 (control) and IM-3 treated zebrafish, respectively (Fig. 6a). There was a significant and negative linear relationship between zebrafish sperm density and IM exposure frequency (Fig. 7a). at all observation times (Fig. 6b-g). There was a significant decline in the percentage of motile sperm with time (i.e. from 5 to $30 \mathrm{spa}$ ) in both IM-treated and untreated zebrafish. There was a significant and negative linear relationship between sperm motility and IM exposure frequency (Fig. 7b-g).

The IM-induced decrease in sperm density and motility recovered during the depuration period. At the end of the depuration period sperm cells in IM-1, IM-2, and IM-3 treated fish had a density and motility similar to that of untreated fish (IM-0) (results not shown).

\subsection{Viability}

\subsubsection{Fertility}

There was a significant fertility difference between IM-3 $q \times \mathrm{IM}-3 \AA$ pairs and

345 controls $(\mathrm{IM}-0 \uparrow \times \mathrm{IM}-0 \AA)($ Fig. $1 \mathrm{c}$ and $\mathrm{d})$. In the male replacement $(\mathrm{IM}-3 \propto \times \mathrm{IM}-0 \AA)$ and

346 female replacement $\left(\mathrm{IM}-0 \bigcirc \times \mathrm{IM}-3{ }^{\AA}\right)$ trials the fertility rate partially recovered (Fig. $1 \mathrm{e}$ and

347 f). There was a significant difference between the male replacement (IM- $3 q \times$ IM- $\left.0{ }^{\lambda}\right)$ and 
348 control $\left(\mathrm{IM}-0 \bigcirc \times \mathrm{IM}-0{ }^{\Uparrow}\right)$ although such a significant difference was not observed between

349 female replacement $(\mathrm{IM}-0 \propto+\mathrm{IM}-3 \overbrace{}^{\Uparrow})$ and control.

\subsubsection{Embryo hatching rates}

The IM-3 $+\times$ IM-3 $\lesssim$ embryos had a significantly higher HR at 48 hpf compared to IM- 0 ㅇ $\times$ IM- $0 \bigcirc$ embryos. A significant difference was not observed in HR at $72 \mathrm{hpf}$. In the male replacement trial, the IM-3 $q \times$ IM- $0{ }^{\lambda}$ embryos had a 48 hpf HR -lower than IM-3 $\bigcirc \times$

IM-3 $\bigcirc$ and higher than IM- $09 \times$ IM- $0 \curvearrowright$ embryos. In the female replacement trial, the IM- 09

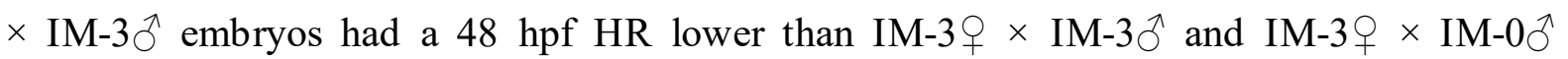
embryos, similar to IM- $0 \propto+$ IM- $0 \curvearrowright$ embryos. We observed no such difference in HR at 72 hpf(Fig. 1c-f).

\subsubsection{Embryo-larvae survival rate}

We found no significant difference in 24-240 hpf embryo-larvae survivability between IM-3q $\times$ IM-3 $\lesssim($ mean \pm S.D; $88.2 \pm 7.7 \%)$ and IM-0 $q \times$ IM-0 $\nrightarrow($ mean \pm S.D; 89.5

$363 \pm 11.0 \%$ ) progeny. We also did not find any significant difference in 24-240 hpf embryonic or larval survival rates between the offspring of replacement trials (male [IM-3q $\times$ IM- $0 \hat{\bigcirc}$; $95.8 \pm 1.2 \%]$ and female $[\mathrm{IM}-0 \propto \times \mathrm{IM}-3 \hat{\jmath} ; 99.2 \pm 1.2 \%])$ and $\mathrm{IM}-3 \propto \times \mathrm{IM}-3 \hat{\jmath}(88.2 \pm 7.7 \%)$

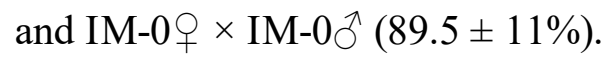

3.8. Larvae morphometric alterations

The IM-exposed groups significantly differed from controls for changes in

370 morphometric ratios at different larval developmental stages (Table 1). In Table 1 all ratios 371 but one (row 19) were different for at least one IM treatment group from control. Significant

372 variations were also observed among all but 4 IM-exposed groups (Table 1, rows 11, 15-16, 
and 18). The variations of 19 morphometric ratios (as dependent variables) at 72, 96, 120, (as the independent variable) by simple regression models as either linear (Table 2, boldface data) or quadratic (Table 2, und erlined data) functions.

3.9. IM-induced changes in vegfaa and igf $2 a$ expression

The expression levels of igf $2 a$ and vegfaa were significantly down-regulated in the ovary of IM-3-treated adult zebrafish relative to untreated fish (IM-0), by 2.10- and 2.30-fold, respectively. A decreased expression level of these four endpoints was also observed in the testes of IM-3-treated adult zebrafish relative to untreated fish, by 2.13-fold and 2.30-fold, respectively.

\section{Discussion}

IM is a class of chemotherapeutic agents with inconclusive reports about its adverse effects on reproduction of humans and laboratory animals. In the current study, for the first time, zebrafish were used as an alternative model to characterize potential IM-induced reproductive effects.

\subsection{Effects of IM on ovary development}

Exposure to IM caused a delay in zebrafish ovarian follicular development that was

393 indicated by the significantly higher presence of early-stage perinucleolar follicles in all three

394 IM-treated groups and a suppression of size in the IM-3 treated group compared to control. In

395 the study of Asadi-Azarbaijani et al. (2017) the treatment of rats on postnatal days 2-4 with

396 IM $(150 \mathrm{mg} / \mathrm{kg})$ led to delay in the formation of primordial follicles, increased density of

397 multi-oocyte follicles, oogonia, and germline clusters, and decreased activation of primordial 
follicles. In brief, the follicular defect was attributed to the inhibitory effect of IM on 1) TK signaling pathways, 2) growth factors, 3) transcription factors, and 4) steroidogenic

400 regulatory proteins that are involved in early folliculogenesis. The inhibiting effect of IM on

401 follicle activation in the Asadi-Azarbaijani et al. (2017) study is also supported by a study

402 that showed significantly decreased numbers of primary follicles, developing Graafian

403 follicles, and developed Graafian follicles in adult IM-treated (50 and $100 \mathrm{mg} / \mathrm{kg}$ for 14 days)

404 rats (Yaghmaei et al., 2009b).

There are also studies in which the exposure to IM led to a significant decrease in total number of ovarian follicles, e.g. a massive follicle loss was reported in IM-treated (2.5, 5, and $10 \mu \mathrm{M}$ for 12, 24, 48 and $72 \mathrm{~h}$ ) ovaries from humans (Bildik et al., 2016). Yildiz et al. (2016) also cited a significant decrease in the ovarian follicle number in IM-treated (25 $\mathrm{mg} / \mathrm{kg} / \mathrm{day}$ for 14 days) rats.

Christopoulos et al. (2008) reported a single case of a 28-year old woman with CML who developed primary ovarian insufficiency after treatment with 400-600 mg/day IM for 2

412 years although the report was criticized by Malozowski et al. (2008) as possibly being only a 413 chance finding. In the study of Schultheis et al. (2012) IM (150 mg/kg/day for $2 \mathrm{months}$ ) had no effect on murine ovary. There was a normal succession of follicle development from the primordial stage to ovulation in leukemic mice.

In the current study, IM-induced defects in folliculogenesis were concentration-

417 dependent (Fig. 4a-e) and consistent with the study of Bildik et al. (2016) in human ovaries.

418 The overall statistical strength of the association was higher at later follicular stages (V and

419 M [Fig. 4d and e]) compared to earlier stages (PN, eCA, and mCA [Fig. 4a-c]), which can be 420 explained by follicles at advanced maturity stages having a higher probability of being atretic 421 (Silva et al., 2012), and therefore more sensitive to IM than earlier gametogenic stages. 
controls, i.e. a decrease in follicle diameters at all gametogenic stages.

Although the smaller follicles in the current study at later gametogenic stages are thought of as a disadvantage for the offspring (Weber et al., 2003), the biological effects of the decrease in the size of follicles at earlier stages (i.e. PN and eCA, Fig. $4 \mathrm{f}$ and $\mathrm{g}$ ) remains unclear.

Cortical alveoli are synthesized endogenously, involving the rough endoplasmic reticulum (ER) and the Golgi complex (Tyler and Sumpter, 1996). Adverse effects of IM on ER function (i.e. the induction of ER stress) have previously been reported (Hu et al., 2012). Thus, the decrease CA follicle size in the ovaries of IM-treated zebrafish compared to control in the current study can be correlated to adverse effects of IM on ER function.

Except for the percent of oocytes in the mCA stage and PN diameter (Fig. $5 \mathrm{c}$ and $\mathrm{f}$ ) we did not find significant differences between the end of the 30-day IM exposure and after 30 days of depuration regarding follicular development (follicle number [Fig. 5a-b, d-e], and diameter [Fig. 5g-j]) at the different gametogenic stages. This suggests that IM may have irreversible effects on zebrafish folliculogenesis after exposure.

4.2. Sperm density and motility

Zebrafish IM exposure led to a significant concentration-dependent decrease in sperm

442 density and motility (Figs. 6 and 7). This is consistent with adult rat and human studies.

443 Decreased sperm cell number at different gametogenic stages was seen in rats exposed to 6-

$44412 \mathrm{mg} / \mathrm{kg}$ for 30 days (Yaghmaei et al., 2009a). Sixty $\mathrm{mg} / \mathrm{kg}$ of IM for 70 days reduced 445 motile sperm number in rats (Novartis Pharmaceuticals Corporation, 2018). Oligospermia 446 was seen in a human who received 400-800 daily for 5 months - Seshadri et al., 2004) and in 
447 a human who received $400 \mathrm{mg}$ daily for 35 months (Mariani et al., 2011). In contrast, no

448 difference in spermatogenesis was observed in IM-treated and untreated adult mice 449 continuously exposed to IM, $150 \mathrm{mg}$ daily, for 2 months (see Apperley, 2009), and normal 450 sperm production was seen in IM-treated leukemic mice $(150 \mathrm{mg} / \mathrm{kg} / \mathrm{day}$ for $2 \mathrm{months})$ 451 (Schultheis et al. (2012)). The latter observation was attributed to the redundancy of the 452 tyrosine protein kinase pools in gonads. A lack of IM-induced change in sperm motility was 453 also observed in rats treated with $\leq 20 \mathrm{mg} / \mathrm{kg}$ attributed to the low IM dose (Novartis 454 Pharmaceuticals Corporation, 2018).

In the current study, the IM-induced decrease in sperm parameters recovered during the depuration period. This agrees with prior studies. An IM-induced 84\% reduction in epididymal sperm in 35-day old mice that received $150 \mathrm{mg} / \mathrm{kg}$ IM from postnatal days 1 to 5 returned to normal when 90 days old (Basciani et al., 2008)) and an IM-induced defect in spermatogenesis in immature rats $(150 \mathrm{mg} / \mathrm{kg}$ on postnatal days 5 to 7$)$ recovered by 11 460 weeks of age (Nurmio et al., 2007).

4.3. Viability

We observed a significant fertility difference between IM-3 $q \times$ IM-3 $\lesssim$ pairs and controls. In the male replacement $(\mathrm{IM}-3 q \times \mathrm{IM}-0 \AA)$ and female replacement $(\mathrm{IM}-0 \bigcirc \times \mathrm{IM}-$ $\left.3{ }^{\Uparrow}\right)$ trials, fertility recovered (increased). In contrast, fertility was not affected in female rats which had received less than the maximum clinical IM dose for 14 days before mating and through day 6 of gestation (Novartis Pharmaceuticals Corporation, 2018).

The IM-3 $q \times$ IM-3 $\lesssim$ subjects had a significantly higher hatching rate at $48 \mathrm{hpf}$ 469 compared to controls $(\mathrm{IM}-0 \bigcirc \times \mathrm{IM}-0$ ^) $(55.2$ vs, $0 \%)$. The lower hatching rate in male 470 replacement trials $\left(\mathrm{IM}-3 \uparrow \times \mathrm{IM}-0{ }^{\widehat{T}}\right)(22.5 \%)$ and lack of hatching in female replacement 471 trials $\left(\mathrm{IM}-0 \bigcirc \times \mathrm{IM}-3 \mathrm{O}^{\Uparrow}\right)(0 \%)$ at $48 \mathrm{hpf}$ indicates that an effect of IM on eggs contributes to 
accelerated hatching. The change in hatching time is an important stress response of fish

473 larvae (Barton, 2002). Hatching is a consequence of hatching enzyme activity and embryo 474 movements (Winnicki et al., 1970; Yamamoto, 1975). Zebrafish tyrosine kinase expression is 475 regulated in the first $24 \mathrm{~h}$ of development, suggesting their role during early embryonic 476 development (Challa and Chatti, 2013). The inhibitory role of IM on tyrosine kinases that 477 control hatching events may contribute to the accelerated embryo hatching produced by IM478 treated fish.

4.4. IM-induced changes in morphometric ratios

There was significant variation between larvae produced by IM-treated and untreated zebrafish with respect to the morphometric measurements (as a sublethal response) (Table 1). The morphometric alterations were dependent on IM exposure frequency (Table 2).

In comparison to morphological based toxicology assays, morphometric based assays are more relevant to fish larvae growth and developmental response to toxins. The MCs are used to assess impact on growth and development of larvae at exposure concentrations well 487 below those that change larvae survival or produce any remarkable increase in gross malformations, as observed in the current study (Prof. Dr. Jennifer L. Freeman, School of Health Sciences, Purdue University; personal communication).

IM-induced congenital malformations have been reported in animals and humans.

491 Exposure of rats to IM (50 mg/kg/day) led to organogenesis defects, while such teratogenic 492 effects were not observed in rabbits (Novartis investigator's brochure and Novartis clinical 493 safety statement [see Schultheis et al., 2012]). Two of 16 infants had minor abnormalities at, or 494 shortly after, birth (Ault et al. (2006)). A study of 180 pregnancies by Pye et al. (2008) 495 disclosed an IM-induced increase in the risk of fetal malformations. 
In the current study three groups of IM-induced morphometric alterations were seen:

497 The first group was present at early larval stages (BL/APB [Table 1, row 7], BL/BD2 [Table

498 1, rows 8, and 13], PoPB/BD2 [Table 1, row 10], BD2/HL [Table 1, row 11], BD1/BD2

499 [Table 1, row 15], and BD1/HL [Table 1, row 16]). The alterations disappeared at advanced

500 stages. The second group occurred only at later larval stages (APB/HL [Table 1, row 19]).

501 The third group was found to be stable through all larval stages (BL/BD1 [Table 1, rows 1, 3,

$5026,12,18,20,23$, and 25], APB/BD1 [Table 1, rows 2, 4, and 21], APB/BD2 [Table 1, rows

503 5, and 22], BL/HL [Table 1, rows 9, and 24], and PoPB/BD1 [Table 1, rows 14, and 26]).

504 The above-mentioned ratios were created from MCs related to body length (BL, HL, 505 APB, and PoPB) and body depth (BD1 and BD2 [i.e. yolk depth/size]). Such MCs of 506 zebrafish larvae have also been considered to characterize the toxicity of other agents (e.g.

507 George et al., 2011; Brannen et al., 2010; Wirbisky et al., 2016).

508 The second and third groups of morphometric ratio changes show the potential to 509 characterize IM-induced responses. In general, a key element complicating the establishment 510 of a link between exposure and a health defect is the time that elapses between exposure and 511 response (Gluckman et al., 2008; Barouki et al., 2012). It may take years for an individual to 512 present a health defect and pass it on to future generations (Jirtle and Skinner, 2007). In

513 zebrafish the morphometric changes that appeared within a short period of exposure to 514 different IM concentrations could predict later-in-life consequences of IM embryonic 515 exposure.

516

517 4.5. Changes in igf $2 a$ and vegfa expression

518 Exposure of female zebrafish to IM led to retardation at the transition of follicles from 519 the PN to the eCA stage (Fig. 3). These types of defects in ovary development have been 520 reported in zebrafish treated with igf2a-inhibitors such as difenoconazole (Teng et al., 2017). 
igf $2 a$ is dynamically expressed during folliculogenesis in zebrafish. Its expression starts to $\mathrm{mm}$ ) and then decreases (Li et al., 2015). Inhibitory effects of IM on the human igf2a

524 homologue (igf2) have been reported (Pink et al., 2005; Belinsky et al., 2008; de Waal, 2009).

525 The concurrent incidence of the transition retardation of ovarian follicles from the PN to the eCA stage with ovarian igf $2 a$ down-regulation in the IM treated zebrafish suggests a role of $\operatorname{igf} 2 a$ in the defect.

In the current study, a decrease ( 6-fold) was observed in the abundance of ovarian follicles at the V stage, i.e. a developmental block in follicular maturation to stage V (Fig. 3d).

530 Recombinant zebrafish igf $2 a$ proteins directly enhance oocyte maturation via igfl receptors 531 (Li et al., 2015). In the zebrafish study of Nelson and Van Der Kraak (2010), recombinant human igf2 stimulated germinal vesicle breakdown in early vitellogenic $(0.35-0.44 \mathrm{~mm})$, midvitellogenic $(0.45-0.56 \mathrm{~mm})$, and full grown $(0.57-0.65 \mathrm{~mm})$ follicles incubated in vitro.

$534 i g f 2 a$ also mediates luteinizing hormone (LH) action on oocyte maturation in zebrafish (Li et al., 2015). These observations may be attributable to either a direct effect of the IM-induced igf $2 a$ decrease on developing follicles or to an indirect disruption of the pituitary-gonadal endocrine system. Endocrine-related side effects of TKIs, e.g. alterations in thyroid function, bone metabolism, linear growth, gonadal function, fetal development, glucose metabolism, and adrenal function were reviewed by Lodish et al. $(2010 ; 2013)$. The effects of IM on

540 different parts of the reproductive endocrine axis in males and females have been seen, e.g.

541 on progesterone, estrogen, follicle stimulating hormone (FSH), and LH concentration in

542 the rat (Yaghmaei et al., 2009a and b), inhibin-B/FSH ratio in the human (Mariani et al., 543 2008), and testosterone in the human (Gambacorti-Passerini et al., 2003).

An IM exposure frequency-dependent decrease in follicle diameters was found at all 545 follicle stages (Figs. $3 \mathrm{f}-\mathrm{j}$ and $3 \mathrm{f}-\mathrm{j}$ ). The vascular network is essential for providing organs 
with oxygen, nutrients, and hormones, as well as removing metabolic waste products (Haigh,

547 2008; Kim et al., 2013). The vegf gene family provides required signals for vasculogenesis

548 (de novo formation of blood vessels) during embryogenesis and for angiogenesis (formation

549 of new blood vessels from preexisting vessels) during organogenesis (Kim et al., 2013).

550 Bahary et al. (2007) isolated a duplicate vegfa locus in zebrafish (vegfaa and vegfab). vegfa expression has been correlated with the proliferation of blood vessels in the ovary in mammals (Phillips et al., 1990; Ravindranath et al., 1992; Kaczmarek et al., 2005). Folliculogenesis is dependent on new capillary vessel proliferation (Ferrara, 2004). McFee et al. (2009) and Artac et al. (2009) cited the involvement of vegfa in rat folliculogenesis. vegfa production in the ovary is critical for normal reproductive function in mammals (Geva and Jaffe, 2000). Oocyte size in adult fish at later ovary stages is determined by the uptake of systemic circulating vitellogenin (Vtg) protein. Vtg is synthesized and secreted by hepatocytes, transported to the ovary via blood, and finally deposited in oocytes as Vtgderived egg yolk proteins (Wallace, 1985; Arukwe and Goksøyr, 2003). Yolk proteins play a

560 key biological role during embryogenesis and larvae development. The decrease in follicle

561 size $\mathrm{s}$ in all follicular stages in IM-treated fish may be attributed to the reduction in angiogenesis (because of vegfaa down-regulation) that led to a decrease in availability of Vtg and maybe endocrine regulators. igf 2 is also involved in angiogenesis (Herr et al., 2003), exerting its angiogenic effects

565 both directly and via a vegfa mediated process (Belinsky et al., 2008).

566 In the current study, a significant decrease in fecundity was observed in IM-treated zebrafish 567 (section 3.5). In the study of Zhu et al. (2015) the number of produced eggs in zebrafish 568 positively correlated with the level of ovary igf $2 a$ expression. $\operatorname{ig} f 2 a$ is dynamically expressed 569 during folliculogenesis in zebrafish (Li et al., 2015). Wang et al. (2011) suggested that 
reduced egg production may reflect a defect in folliculogenesis. Therefore, the decreased fecundity observed here can be attributed to the IM-induced reduction in igf $2 a$ mRNA. decrease in sperm density (Figs. 6a and 7a). The presence of igf2a in zebrafish testes has been cited by Irwin (2011), Nóbrega et al. (2015), Safian et al. (2016), and Teng et al. (2017). igf2 has a selective paracrine or autocrine role in the regulation of spermatogonial proliferation during spermatogenesis (Gupta, 2005). In humans igf2 promotes the differentiation of spermatogonia into primary spermatocytes (Nakayama et al., 1999). The significant decrease in sperm density in IM-treated zebrafish may be attributed to the reduction in spermatogonial proliferation and differentiation due to testis $i g f 2 a$ down-regulation. vegfa is present during testis morphogenesis and expressed by Sertoli cells which play an important role in testis formation and function in the human (Funke et al., 2010). Alterations in vegfa expression have frequently been correlated to testis developmental and functional

584 impairments in the mouse (Korpelainen et al., 1998); rat (Bott et al., 2006; Baltes-Breitwisch

585 et al., 2010) and human (Funke et al., 2010). The vegf protein is present in human spermatids,

586 Sertoli and Leydig cells, and seminal plasma (Obermair et al., 1999). vegf has an important

587 role in human and murine sperm physiology, maturation, and fertility (Obermair et al., 1999;

588 Nalbandian et al., 2003). The effects of the protein on human sperm motility (Iyibozkurt, 589 2008) and survival (Attar et al., 2005) have been cited. The inhibitory effect of IM on vegf 590 expression was cited in mammals (Legros et al., 2004; Raimondi et al; 2014). The concurrent 591 reduction in the number of motile sperm and vegfaa expression in IM-treated zebrafish testis 592 in the current study suggest vegfaa down-regulation can be considered as one of reasons for 593 sperm success failure. 
Although we did not find a significant difference between IM-treated and untreated zebrafish concerning embryo-larvae survival in the current study (see section 3.7.3), we

596 found significant $\mathrm{MC}$ ratio differences s (Table 1). It is clearly evident that igf2 is important 597 during post-hatching development in teleosts, possibly as a local paracrine and/or autocrine 598 regulator of tissue growth (Wood et al., 2005). IM-induced morphometric changes (Table 1) 599 in the current study were detected in characteristics related to the longitudinal axis of larvae 600 body, therefore the IM-induced changes in MC ratios can be attributed to igf $2 a$ down601 regulation.

602 In conclusion, in the current study the same experimental setting was used for analysis 603 of gamete quality and breeding and offspring studies. Our findings were very much in line 604 with the few available experimental results cited for humans and other mammalian vertebrates. Here, for the first time a non-mammalian vertebrate was efficiently utilized to provide new data to help clarify the adverse effects of IM on the process of reproduction. In 607 the current study the zebrafish model enabled us to further characterize IM-induced 608 alterations in reproductive success. This suggests that zebrafish can be considered as a suitable laboratory model not only to explain conflicting data about the effects of TKIs (such as IM) on fertility and teratogenicity, but also to uncover underlying molecular mechanisms

611 of TKI's adverse effects reproductive processes. This follows the suggestion that zebrafish 612 may help to establish a new path for improving fertility and treatment of ovarian disorders in 613 vertebrates (Biswas and Maitra, 2017).

\section{Acknowledgments}

616 The authors are grateful to Dr. Kiranam Chatti (University of Hyderabad, India) and 617 Dr. Kirsi Jahnukainen (University of Helsinki, Finland) for their linguistic editing and 
scientific comments during preparation of this report. We gratefully acknowledge Osvah

619 Pharmaceutical Co. (Tehran, Iran), for providing the imatinib tablet excipients.

620

621 References

622 Adkins CE, Mittapalli RK, Manda VK, Nounou MI, Mohammad AS, Terrell TB, Bohn KA, YaseminC, Grothe TR, Lockman JA, Lockman PR. 2013. P-glycoprotein mediated efflux limits substrate and drug uptake in a preclinical brain metastases of breast cancer model. Front Pharmacol 4: 1-8.

Ali R, Ozkalemkas F, Ozcelik T, Ozkocaman V, Ozkan A. 2006. Imatinib and Pregnancy. Journal of Clinical Oncology, 24(23): 3812-3813.

Apperley J. 2009. Issues of imatinib and pregnancy outcome. J Natl Compr Cancer Netw 7(10): 1050-1058.

Artac RA, McFee RM, Smith RA, Baltes-Breitwisch MM, Clopton DT, Cupp AS. 2009. Neutralization of vascular end othelial growth factor antiangiogenic isoforms is more effective than treatment with proangiogenic isoforms in stimulating vascular development and follicle progression in the perinatal rat ovary. Biol Reprod 81(5): 978-988.

Arukwe A, Goksøyr A. 2003. Eggshell and egg yolk proteins in fish: hepatic proteins for the next generation: oogenetic, population, and evolutionary implications of endocrine disruption. Comp Hepatol 2(1): 4.

Asadi-Azarbaijani B, Santos RR, Jahnukainen K, Braber S, van Duursen MB, Toppari J, Saugstad OD, Nurmio M, Oskam IC. 2017. Developmental effects of imatinib mesylate on follicle assembly and early activation of primordial follicle pool in postnatal rat ovary. Reprod Biol 17(1): 25-33. 
Attar E, Balcik P, Bulgurcuoglu S, Ozsait B, Serdaroglu H, Hekim N. 2005. The role of vascular endothelial growth factor (VEGF) on sperm motility and survival in endometriosis. Fertil Steril 84: S201.

Ault P, Kantarjian H, O'Brien S, Faderl S, Beran M, Rios MB, Koller C, Giles F, Keating M, Talpaz M, Cortes J. 2006. Pregnancy among patients with chronic myeloid leukemia treated with imatinib. J Clin Oncol 24: 1204-1208.

Azanza JR, Sádaba B, Díez N (2018) Comparative Pharmacology of Tyrosine Kinase Inhibitors for the Treatment of Chronic Myeloid Leukemia. Int J Clin Pharmacol Pharmacother 3: 134 .

Bahary N, Goishi K, Stuckenholz C, Weber G, Leblanc J, Schafer CA, Berman SS, Klagsbrun M, Zon LI. 2007. Duplicate VegfA genes and orthologues of the KDR receptor tyrosine kinase family mediate vascular development in the zebrafish. Blood 110(10): 3627-36.

Baltes-Breitwisch MM, Artac RA, Bott RC, McFee RM, Kerl JG, Clopton DT, Cupp AS. 2010. Neutralization of vascular end othelial growth factor antiangiogenic isoforms or administration of proangiogenic isoforms stimulates vascular development in the rat testis. Reproduction 140: 319-329.

Barouki, R., Gluckman, P. D., Grandjean, P., Hanson, M., Heindel, J. J. 2012. Developmental origins of non-communicable disease: implications for research and public health Environ Health 11: 1-9.

Barton, B.A. 2002. Stress in fishes: A diversity of responses with particular reference to changes in circulating corticosteroids. Integr Comp Biol 42: 517-525.

Basciani S, De Luca G, Dolci S, et al. 2008. Platelet-derived growth factor receptor betasubtype regulates proliferation and migration of gonocytes. Endocrinology 149: $6226-6235$. 
Bay K, Bjerrum OW, Olsson-Strömberg U, Porkka K, Inge Dufva H. 2013. Reproductive hormone profiles during imatinib therapy in men with chronic myeloid leukemia. Andrology 2: 105.

Belinsky MG, Rink L, Cai KQ, Ochs MF, Eisenberg B, Huang M, von Mehren M, Godwin AK. 2008. The insulin-like growth factor system as a potential therapeutic target in gastrointestinal stromal tumors. Cell Cycle 7(19): 2949-55.

Bildik G, Akin N, Urman D, Keles I, Balaban B, Urman B, Oktem O. 2016. Imatinib mesylate accelerates follicle death and is not protective against chemotherapy induced damage in human ovary. Fertil Steril 106(3): e81.

Bott RC, McFee RM, Clopton DT, Toombs C, Cupp AS. 2006. Vascular end othelial growth factor and kinase domain region receptor are involved in both seminiferous cord formation and vascular development during testis morphogenesis in the rat. Biol Reprod 75: 56-67.

Brannen KC, Panzica-Kelly JM, Danberry TL, Augustine-Rauch KA. 2010. Development of a zebrafish embryo teratogenicity assay and quantitative prediction model. Birth Defects Res B Dev Reprod Toxicol 89: 66-77.

Braunbeck T, Lammer E. 2006. Fish embryo toxicity assays. Aquatic Ecology \& Toxicology Department of Zoology University of Heidelberg. Im Neuenheimer Feld 230 D-69120 Heidelberg Germany.

Challa, A.K., and Chatti, K. 2013. Conservation and early expression of zebrafish tyrosine kinases support the utility of zebrafish as a model for tyrosine kinase biology. Zebrafish 10(3): 264-74.

Christopoulos C, Dimakopoulou V, Rotas E. 2008. Primary ovarian insufficiency associated with imatinib therapy. N Engl J Med 358: 1079-80. 
de Waal PP. 2009. Hormonal regulation of spermatogenesis in Zebrafish. Thesis, Department of Biology, Science Faculty, University of Utrecht, The Netherlands.

Eechoute K, Sparreboom A, Burger H, Franke RM, Schiavon G, Verweij J, Loos WJ, Wiemer EA, Mathijssen RH. 2011. Drug transporters and imatinib treatment: implications for clinical practice. Clin Cancer Res 17(3): 406-15.

Ferrara N. 2004. Vascular endothelial growth factor: basic science and clinical progress. Endocrine Reviews 25: 581-611.

Finn RN, Fyhn HJ, Henderson RJ, Evjen MS. 1996. The sequence of catabolic substrate oxidation and enthalpy balance of developing embryos and yolk-larvae of turbot, Scophthalmus maximus L. Comp Biochem Physiol A115: 133-151.

Funke S, Flach E, Kiss I, Sándor J, Vida G, Bódis J, Ertl T. 2010. Male reproductive tract abnormalities: More common after assisted reproduction. Early Hum Dev 86:547-550.

Gambacorti-Passerini C, Tornaghi L, Cavagnini F, Rossi P, Pecori-Giraldi F, Mariani L, Cambiaghi N, Pogliani E, Corneo G, Gnessi L. 2003. Gynaecomastia in men with chronic myeloid leukaemia after imatinib. Lancet 361(9373):1954-6.

George S, Xia T, Rallo R, Zhao Y, Ji Z, Lin S, Wang X, Zhang H, France B, Schoenfeld D, Damoiseaux R, Liu R, Lin S, Bradley KA, Cohen Y, Nel AE. 2011. Use of a highthroughput screening approach coupled with in vivo zebrafish embryo screening to develop hazard ranking for engineered nanomaterials. ACS Nano 5(3): 1805-1817.

Geva E, Jaffe RB. 2000. Role of vascular end othelial growth factor in ovarian physiology and pathology. Fertil Steril. 74: 429-438.

Gluckman, P.D., Hanson, M.A., Cooper, C., Thornburg, K.L. 2008. Effect of in utero and early-life conditions on adult health and disease. N. Engl. J. Med. 359, 61-73.

Goldsmith P, Solari R. 2003. The role of zebrafish in drug discovery. Drug Discov World Spring. 
Grush J, Noakes DLG, Moccia RD. 2004. The efficacy of clove oil as an anesthetic for the zebrafish, Danio rerio (Hamilton). Zebrafish 1(1): 46-53.

Guide for the Care and Use of Laboratory Animals. 2011. National Research Council (US) Committee for the Update of the Guide for the Care and Use of Laboratory Animals. 8th edition. Washington (DC): National Academies Press (US).

Gupta GS. 2005. Proteomics of spermatogenesis. Springer, Boston, MA ISBN 978-0-38727655-7.

Gupta T, Mullins MC. 2010. Dissection of organs from the adult zebrafish. J Vis Exp 37: 1717.

Hagedorn HH, Kunkel JG. 1979. Vitellogenin and vitellin in insects. A Rev Entomol 24: $475-505$.

Hagedorn M, Carter VL. 2011. Zebrafish reproduction: revisiting in vitro fertilization to increase sperm cryopreservation success. PLoS ONE 6(6): e21059.

Haigh JJ. 2008. Role of VEGF in organogenesis. Organogenesis 4(4): 247-56.

Heinrich MC, Griffith DJ, Druker BJ, Wait CL, Ott KA, Zigler AJ. 2000. Inhibition of c-kit receptor tyrosine kinase activity by STI 571, a selective tyrosine kinase inhibitor. Blood 96: 925-932.

Hensley ML, Ford JM. 2003. Imatinib treatment: Specific issues related to safety, fertility, and pregnancy. Semin Hematol 40: 21-25.

Herr F, Liang OD, Herrero J, Lang U, Preissner KT, Han VK, Zygmunt M. 2003. Possible angiogenic roles of insulin-like growth factor II and its receptors in uterine vascular adaptation to pregnancy. J Clin Endocrinol Metab 88(10): 4811-7. 4784. 
Holdhoff M, Supko JG, Gallia GL, Hann CL, Bonekamp D, Ye X, Cao B, Olivi A, Grossman SA. 2010. Intratumoral concentrations of imatinib after oral administration in patients with glioblastoma multiforme.J Neurooncol 97(2): 241-5.

Hoo JY, Kumari Y, Shaikh MF, Hue SM, Goh BH. 2016. Zebrafish: A versatile animal model for fertility research. BioMed Res Int 9732780.

Hu W, Lu S, McAlpine I, Jamieson JD, Lee DU, Marroquin LD, Heyen JR, Jessen BA. 2012. Mechanistic investigation of imatinib-induced cardiac toxicity and the involvement of c-Abl Kinase. Toxicol Sci 129(1): 188-199.

Ingermann RL, Schultz CLF, Kanuga MK, Wilson-Leedy JG. 2011. Metabolism of motile zebrafish sperm. Comp Biochem Physiol A 158: 461-467.

Irwin DA. 2011. The regulation and function of the ovarian-derived insulin like growth factor system in zebrafish (Danio rerio). MSc thesis in Integrative Biology, The University of Guelph, Ontario, Canada.

Iyibozkurt AC, Balcik P, Bulgurcuoglu S, Arslan BK, Attar R, Attar E. 2009. Effect of vascular endothelial growth factor on sperm motility and survival. Reprod Biomed Online 19(6): 784-788.

James C, Trouette H, Marit G, Cony-Makhoul P, Mahon FX. 2003. Histological features of acute hepatitis after imatinib mesylate treatment. Leukemia 17(5): 978-9.

Jirtle, R.L., Skinner, M.K. 2007. Environmental epigenomics and disease susceptibility. Nat. Rev. Genet. 8, 253-262.

Kaczmarek MM, Schams D, Ziecik AJ. 2005. Role of vascular endothelial growth factor in ovarian physiology—an overview. Reprod Biol 5: 111-136.

Karaman MW, Herrgard S, Treiber DK, Gallant P, Atteridge CE, Campbell BT, Chan KW, Ciceri P, Davis MI, Edeen PT, Faraoni R, Floyd M, Hunt JP, Lockhart DJ, Milanov ZV, Morrison MJ, Pallares G, Patel HK, Pritchard S, Wodicka 
LM, Zarrinkar PP. 2008. A quantitative analysis of kinase inhibitor selectivity. Nat Biotechno 126: 127-132.

Kent ML, Spitsbergen JM, Matthews JM, Fournie JW, Westerfield M. Diseases of zebrafish in research facilities. Zebrafish International Resource Center, Eugene, OR, 2002. https://zebrafish.org/wiki/health/disease manual/start (accessed on 11-10-2018).

Kerr JB, Hutt KJ, Cook M, Speed TP, Strasser A, Findlay JK, Scott CL. 2012. Cisplatininduced primordial follicle oocyte killing and loss of fertility are not prevented by imatinib. Nat Med 18: 1170-1172.

Kim SH, Schmitt CE, Woolls MJ, Holland MB, Kim JD, Jin SW. 2013. Vascular end othelial growth factor signaling regulates the segregation of artery and vein via ERK activity during vascular development. Biochem Biophys Res Commun 430(4): 1212-6.

King Heiden T, Carvan MJ III, Hutz RJ. 2006. Inhibition of follicular development, vitellogenesis, and serum $17 \beta$-estradiol concentrations in zebrafish following chronic, sublethal dietary exposure to 2,3,7,8-Tetrachlorodibenzo-p-Dioxin. Toxicol Sci 90(2): 490-499.

Kinkel, M.D., Eames, S.C., Philipson, L.H., Prince, V.E. 2010. Intraperitoneal injection into adult zebrafish. J. Vis. Exp. (42), e2126. Samaee SM, Manteghi N, Yokel RA, Mohajeri-Tehrani MR. 2018. Morphometric characteristics and time to hatch as efficacious indicators for potential nanotoxicity assay in zebrafish. Environ Toxicol Chem 37(12): 3063-3076.

Korpelainen E, Karkkainen M, Tenhunen A, Lakso M, Rauvala H, Vierula M, Parvinen M, Alitalo K. 1998. Overexpression of VEGF in testis and epididymis causes infertility in transgenic mice: evidence for nonendothelial targets for VEGF. J Cell Biol 143: $1705-1712$. 
Legros L, Bourcier C, Jacquel A, Mahon FX, Cassuto JP, Auberger P, Pagès G. 2004. Imatinib mesylate (STI571) decreases the vascular endothelial growth factor plasma concentration in patients with chronic myeloid leukemia. Blood 104(2):495-501.

Li J, Chu L, Sun X, Liu Y, Cheng CH. 2015. IGFs mediate the action of LH on oocyte maturation in zebrafish. Mol Endocrinol 29(3): 373-383.

Livak KJ, Schmittgen TD. 2001. Analysis of relative gene expression data using real-time quantitative PCR and the $2^{-\Delta \Delta C T}$ method. Method 25:402-408.

Lodish MB, Stratakis CA. 2010. Endocrine side effects of broad-acting kinase inhibitors. Endocr Relat Cancer 17: R233-R244.

Lodish MB. 2013. Kinase Inhibitors: Adverse effects eelated to the endocrine system. J Clin 799 Endocrinol Metab 98(4): 1333-1342.

Loren AW, Mangu PB, Beck LN, Brennan L, Magdalinski AJ, Partridge AH, Quinn G, Wallace WH, Oktay K, American Society of Clinical Oncology. 2013. Fertility

Maley D, Laird AS, Rinkwitz S, Becker TS. 2013. A simple and efficient protocol for the 805

806 treatment of zebrafish colonies infected with parasitic nematodes. Zebrafish 10(3):

Malozowski S, Nelson L, Calis KA. 2008. More on ovarian insufficiency with imatinib. N Engl J Med 358: 2648-2649.

Mariani S, Basciani S, Fabbri A et al. 2011. Severe oligozoospermia in a young man with 810 chronic myeloid leukemia on long-term treatment with imatinib started before puberty. Fertil Steril 95: 1120.e15-e17. 
812 Mariani S, Giona F, Basciani S, Brama M, GnessiLow L. 2008. Bone density and decreased 813 inhibin-B/FSH ratio in a boy treated with imatinib during puberty. Lancet 372 : 111$814 \quad 112$.

815 Matthews JL. 2004. Common diseases of laboratory zebrafish. Methods Cell Biol 77:617$816 \quad 643$.

817 Mauduit C, Hamamah S, Benahmed M. 1999 Stem cell factor/c-kit system in 818 spermatogenesis. Hum Reprod Update 5:535-545.

819 McFee RM, Artac RA, McFee RM, Clopton DT, Smith RA, Rozell TG, Cupp AS. 2009. 820 Inhibition of vascular end othelial growth factor receptor signal transduction blocks follicle progression but does not necessarily disrupt vascular development in perinatal

Miranda AC, Bazzoli N, Rizzo E, Sato Y. 1999. Ovarian follicle atresia in two teleost 824 species: a histological and ultrastructural study. Tissue Cell 31(5):480-488.

Mughal TI, Schrieber A. 2010. Principal long-term adverse effects of imatinib in patients with chronic myeloid leukemia in chronic phase. Biologics: Targets \& Therapy 4: $315-323$.

Nakayama Y, Yamamoto T, Abé SI. 1999. IGF-I, IGF-II and insulin promote differentiation 830 of spermatogonia to primary spermatocytes in organ culture of newt testes. Int $\mathrm{J}$ Dev

Nalbandian A, Dettin L, Dym M, Ravindranath N. 2003. Expression of vascular end othelial 832 growth factor receptors during male germ cell differentiation in the mouse. Biol Reprod 69(3):985-94.

834 Nelson SN, Van Der Kraak G. 2010.The role of the insulin-like growth factor (IGF) system 835 in zebrafish (Danio rerio) ovarian development. Gen Comp Endocrinol 168: 103-110. 
836 Nóbrega RH, Morais RD, Crespo D, de Waal PP, de França LR, Schulz RW, Bogerd J. 2015.

837 Fsh stimulates spermatogonial proliferation and differentiation in zebrafish via $\operatorname{Ig} 3$. $838 \quad$ Endocrinology 156(10): 3804-17.

839 Novak M, Žegura B, Nunić J, Gajski G, Gerić M, Garaj-Vrhovac V, Filipič M. 2017. 840 Assessment of the genotoxicity of the tyrosine kinase inhibitor imatinib mesylate in cultured fish and human cells. Mutat Res. 814: 14-21.

842 Novartis Pharmaceuticals Corporation. Gleevec ${ }^{\circledR}$ Highlights of Prescribing Information. Revised 7/2018. East Hanover, New Jersey. Available at: http://www.pharma.us.novartis.com/product/pi/pdf/gleevec tabs.pdf (accessed on 2401-2019).

Nurmio M, Toppari J, Zaman F, et al. 2007 Inhibition of tyrosine kinases PDGFR and C-Kit 847 by imatinib mesylate interferes with postnatal testicular development in the rat. Int $\mathrm{J}$ Androl 30:366-376.

849 Obermair A, Obruca A, Pöhl M, Kaider A, Vales A, Leodolter S, Wojta J, Feichtinger W. 1999. Vascular endothelial growth factor and its receptors in male fertility. Fertil Steril 72: 269-275.

852 Ohkubo N, Matsubara T. 2002. Sequential utilization of free amino acids, yolk proteins and lipids in developing eggs and yolk-sac larvae of barfin flounder Verasper moseri. Mar Biol 140:187-196.

855 Ohyashiki K, Kuriyama Y, Nakajima A, Tauchi T, Ito Y, Miyazawa H, Kimura Y, Serizawa 856 H, Ebihara Y. 2002. Imatinib mesylate-induced hepato-toxicity in chronic myeloid 857 leukemia demonstrated focal necrosis resembling acute viral hepatitis. Leukemia 858 16(10): 2160-1. 
Patel BB, He YA, Li X.-M, Frolov A, Vanderveer L, Slater C, Schilder RJ, Mehren MV, Godwin AK, Yeung AT. 2008. Molecular mechanisms of action of imatinib mesylate in human ovarian cancer: a proteomic analysis. Cancer Genom Proteom 5: 137-150.

862 Peng B, Lloyd P, Schran H. 2005. Clinical pharmacokinetics of imatinib. Clin Pharmacokinet 44(9): 879-94.

Phillips HS, Hains J, Leung DW, Ferrara N. 1990. Vascular endothelial growth factor is expressed in rat corpus luteum. Endocrinology 127: 965-967.

Pink D, Schoeler D, Lindner T, Thuss-Patience PC, Kretzschmar A, Knipp H, Vanhoefer U, Reichardt P. 2005. Severe hypoglycemia caused by paraneoplastic production of IGF-II in patients with advanced gastrointestinal stromal tumors: a report of two cases. J Clin Oncol 23: 6809-6811.

Prabhash K, Sastry PSRK, Biswas G, Bakshi A, Prasad N, Menon H, Parikh PM. 2005. Pregnancy outcome of two patients treated with imatinib. Ann Oncol Annals of Oncology 16(12): 1983-1984.

Pye SM, Cortes J, Ault P, Hatfield A, Kantarjian H, Pilot R, et al. 2008 The effects of imatinib on pregnancy outcome. Blood 111:5505-8.

Raimondi C, Fantin A, Lampropoulou A, Denti L, Chikh A, Ruhrberg C. 2014. Imatinib inhibits VEGF-independent angiogenesis by targeting neuropilin 1-dependent ABL1 activation in endothelial cells. J Exp Med 211(6): 1167-83.

Ravindranath N, Little-Ihrig L, Phillips HS, Ferrara N, Zeleznik AJ. 1992. Vascular 879 end othelial growth factor messenger ribonucleic acid expression in the primate ovary. Endocrinology 131: 254-260. 172. 
884 Safian D, Morais RD, Bogerd J, Schulz RW. 2016. Igf binding proteins protect

885

886

887

888

889

890

891

892

893

894

895

896

897

898

899

900

901

902

903

904

905

906

907

908 undifferentiated spermatogonia in the zebrafish testis against excessive differentiation. Endocrinology 157(11): 4423-4433.

Samaee S.-M, Manteghi N, Yokel RA, Mohajeri-Tehranid MR. 2018. Morphometric characteristics and time to hatch as efficacious indicators for potential nanotoxicity assay in zebrafish. Environ Toxicol Chem 37(12): 3063-3076.

Samaee SM, Patzner RA, Mansour N. 2009. Morphological differentiation within the population of Siah Mahi, Capoeta capoeta gracilis, (Cyprinidae, Teleostei) in a river of the south Caspian Sea basin: a pilot study. J Appl Ichthyol 25: 583-590.

Samaee SM. 2015. Experimental assessment of the efficacy of five veterinary broadspectrum anthelmintics to control the intestinal capillariasis in zebrafish (Danio rerio). Zebrafish. 12(3): 255--67.

Samaee, S.-M., Rabbani, S., Jovanović, B., Mohajeri-Tehrani, M.R., Haghpanah, V. 2015. Efficacy of the hatching event in assessing the embryo toxicity of the nano-sized $\mathrm{TiO}_{2}$ particles in zebrafish: A comparison between two different classes of hatchingderived variables. Ecotox. Environ. Safe. 116, 121-128.

Schultheis B, Nijmeijer BA, Yin H, Gosden RG, Melo JV. 2012. Imatinib mesylate at therapeutic doses has no impact on folliculogenesis or spermatogenesis in a leukaemic mouse model. Leuk Res 36: 271-274.

Selman K, Wallace RA, Sarka A, Qi X. 1993. Stages of oocyte development in the zebrafish, Brachydanio rerio. J Morphol 218: 203-224.

Seshadri T, Seymour JF, McArthur GA. 2004. Oligospermia in a patient receiving imatinib therapy for the hypereosinophilic syndrome. N Engl J Med 351:2134-2135.

Silva P, Rocha MJ, Cruzeiro C, Malhão F, Reis B, Urbatzka R, Monteiro RAF, Rocha E. 2012. Testing the effects of ethinylestradiol and of an environmentally relevant 
mixture of xenoestrogens as found in the DouroRiver (Portugal) on the maturation of fish gonads-A stereological study usingthe zebrafish (Danio rerio) as model. Aquat Toxicol 124: 1-10.

912 Soriano P. 1994 Abnormal kidney development and hematological disorders in PDGF betareceptor mutant mice. Genes Dev 8:1888-1896.

914 Soriano P. 1997 The PDGF alpha receptor is required for neural crest cell development and for normal patterning of the somites. Development 124:2691-2700.

Subhasri B, Sudipta M. 2017. Let's talk and grow together: a bidirectional communication between granulosa- and oocyte-derived factors in the ovary. Glob J Reprod Med 1(4): 555569.

Teng M, Qi S, Zhu W, Wang Y, Wang D, Yang Y, Li H, Li C, Dong K, Wang C. 2017. Sex920 specific effects of difenoconazole on the growth hormone endocrine axis in adult zebrafish (Danio rerio). Ecotoxicol Environ Saf 144: 402-408.

Tybulewicz VL, Crawford CE, Jackson PK, et al. Neonatal lethality and lymphopenia in mice with a homozygous disruption of the c-abl proto-oncogene. Cell 1991;65:1153-1163.

Tyler CR, Sumpter JP. Oocyte growth and development in teleosts. 1996. Rev Fish Biol Fish 925 6: $287-318$.

Van Stappen G. 1996. Artemia. In: Manual on the production and use of live food for aquaculture. Eds. Lavens, P., Sorgeloos, P. FAO Fish Tech Pap. No. 361. FAO, Rome.

Varga ZM. 2011. Aquaculture and husbandry at the Zebrafish international resource center. Method Cell Biol 104.

Wallace RA. 1985. Vitellogenesis and oocyte growth in non-mammalian vertebrates. In: Browder LW, ed, Developmental Biology, Plenum Press, New York, 1:127-177. 
Wang J, Zhu X, Zhang X, Zhao Z, Liu H, George R, Wilson-Rawls J, Chang Y, Chen Y. 2011. Disruption of zebrafish (Danio rerio) reproduction upon chronic exposure to $\mathrm{TiO}_{2}$ nanoparticles. Chemosphere 83: 461-467.

Weber LP, Hill RL Jr, Janz DM. 2003. Developmental estrogenic exposure in zebrafish (Danio rerio): II. Histological evaluation of gametogenesis and organ toxicity. Aquat Toxicol 63: 431-446.

Westerfield M. 2000. The Zebrafish book: A Guide for the Laboratory Use of Zebrafish (Danio rerio). University of Oregon Press, Eugene, USA.

Westerfield M. 2007. The Zebrafish Book. A Guide for the Laboratory Use of Zebrafish (Danio rerio), 5th Edition. University of Oregon Press, Eugene.

Winnicki A, Radziun MS, Radziun K. 1970. Structural and mechanical changes in the egg membranes of Salmo gairdneri Rich. during the period of hatching of the larvae. Acta Ichth Piscat 1: 7-18.

Wirbisky SE, Weber GJ, Sepúlveda MS, Lin T.-L, Jannasch AS, Freeman JL. 2016. An embryonic atrazine exposure results in reproductive dysfunction in adult zebrafish and morphological alterations in their offspring. Sci Rep6: 21337.

Wolff $\mathrm{NC}^{1}$, Richardson JA, Egorin M, Ilaria RL Jr. 2003. The CNS is a sanctuary for leukemic cells in mice receiving imatinib mesylate for Bcr/Abl-induced leukemia. Blood 101(12): 5010-3.

Wood AW, Duan C, Bern HA. 2005. Insulin-like growth factor signaling in fish. Int Rev Cytol 243: 215-85.

Yaghmaei P, Parivar K, Gharibi A, Nabiuni M. 2009a. The biological effects of imatinib on male fertility of wistar rats. Int J Fertil Steril 3(3): 135-142.

Yaghmaei P, Parivar K, Jalalvand F. 2009b. Effect of imatinib on the oogenesis and pituitaryovary hormonal axis in female wistar Rat Int J Fertil Steril 3(1): 11-16. 
958 Yamamoto, M., 1975. Hatching gland and hatching enzyme. In: Yamamoto T, ed, Medaka (Killifish): Biology and Strains. Keigaku Pub Co, Tokyo, pp 73-79.

960 Yang H, Jones C, Varga ZM, Tiersch TR. 2007. Development of a simplified and 961 standardized protocol with potential for high-throughput for sperm cryopreservation 962 in zebrafish Danio rerio. Theriogenology 68(2): 128-136.

963 Yildiz C, Kacan T, Akkar OB, Karakus S, Seker M, Kacan SB, Ozer H, Cetin A. 2016. Effect 964 of imatinib on growth of experimental endometriosis in rats. Eur J Obstet Gynecol Reprod Biol 197: 159-63.

966

Zamah AM, Mauro MJ, Druker BJ, Oktay K, Egorin MJ, Cedars MI, Rosen MP. 2011. Will 967 imatinib compromise reproductive capacity? The Oncologist 16: 1422-1427.

968

Zhang Y, Qiao H, Chen C, Wang Z, Xia X. 2016. Determination of nitrofurans metabolites 969 residues in aquatic products by ultra-performance liquid chromatography-tandem mass spectrometry. Food Chem 192: 612-7.

971

Zhu Y, Ma X, Su G, Yu L, Letcher RJ, Hou J, Yu H, Giesy JP, Liu C. 2015. Environmentally 972 Relevant Concentrations of the flame retardant tris (1,3-dichloro-2-propyl) phosphate inhibit growth of female zebrafish and decrease fecundity. Environ Sci Technol

974 49(24): 14579-87.

975

976

977

978

979

980

981

982 


\section{$983 \underline{\text { Tables }}$}

984 Table 1. IM-induced changes in larval morphometric ratios.

985 Footnote $\rightarrow$ Values superscripted with the same letter are not significantly different. See the 986 legend of Figure 1 for abbreviations of the morphometric ratios. Number of specimens $(\mathrm{n})=$ 98720.

988

989 Table 2. Regression equations, correlation $\left(r^{2}\right), \mathrm{F}$ and $p$ values of the significant relationships 990 found between the larval morphometric ratios and the frequency of exposure of adult 991 zebrafish to IM.

992 Footnote $\rightarrow$ The boldface and underlined data show morphometric ratios that are correlated 993 to the frequency of exposure to IM by simple regression models in the form of a linear and 994 quadratic function, respectively. See the legend of Figure 1 for abbreviations of the 995 morphometric ratios.

996

997

998

999

1000

1001

1002

1003

1004 
1006

1007

1008

1009

1010

1011

1012

1013

1014

1015

1016

1017

1018

1019

1020

1021

1022

1023

1024

1025

1026

1027

1028

1029

1030

\section{Figures}

Fig. 1. Observation time points, whole-body zebrafish sagittal section, breeding trials, and morphometric characteristics. (a) Observation time points of zebrafish embryos and larvae. (b) Whole-body zebrafish, paraffin embedded, and H \& E stained. Sagittal orientation, dorsal up.

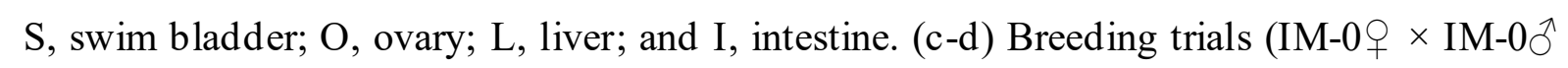

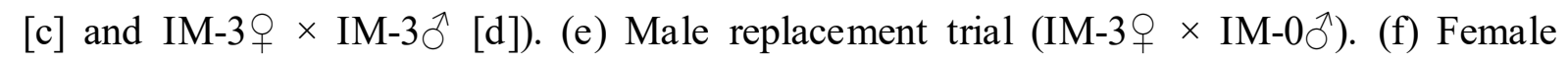

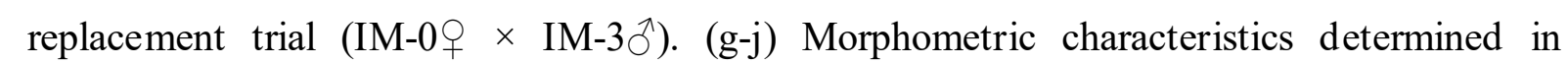
zebrafish embryos and larvae. The landmarks drawn on the schematics of the zebrafish larvae at 48, 72, 96, and $120 \mathrm{hpf}$ depict the characteristics utilized for screening IM-induced responses. BL (total body length): greatest horizontal body distance - anterior-most part of head to the end of body. APB (anterior part of the body): anterior-most part of head to the posterior-most insertion of yolk sac. PoPB (posterior part of body): the posterior-most insertion of yolk sac to the end of body. HL (head length): anterior-most part of head to the place where the head is connected to the body. BD1 (body depth 1): vertical distance from posterior-most insertion of yolk sac to upper surface of body. BD2 (body depth 2): greatest vertical body distance. Fifteen ratios were calculated from the six morphometric characteristics BL/APB, BL/PoPB, BL/BD1, BL/BD2, BL/HL, APB/PoPB, APB/BD1, APB/BD1, APB/HL, PoPB/BD1, PoPB/BD2, PoPB/HL, BD1/BD2, BD1/HL, and BD1/HL.

Fig. 2. Follicles at different gametogenic stages (a-h) and atretic follicles (i-1). (a) Perinucleolus stage (PN); (b,c) early cortical alveolus stage (eCA); (d,e) mid-cortical alveolus stage (mCA); (f-g) vitellogenic stage (V); (h) mature stage (M), and (i-1) examples of atretic oocytes at mature stage. 
1031 Fig. 3. Folliculogenesis in untreated (control) and IM-treated fish. Percentage (a, b, c, d, and

1032 e) and diameter ( $\mu \mathrm{m}$; f, g, h, i, and j) of ovarian follicles at various gametogenic stages. See 1033 the legend of Figure 2 for the abbreviation of follicular stages. Results that do not share the 1034 same letter are significantly different. $n=32$.

1035

1036 Fig. 4. Percentage (a, b, c, d, and e) and diameter (f, g, h, i, and j) of follicles at various stages

1037 in relationship to the frequency of IM exposure. See the legend of Figure 2 for the 1038 abbreviation of follicular stages. $\mathrm{n}=32$.

1039

1040 Fig. 5. Folliculogenesis (percentage [a, b, c, d, and e] and diameter [f, g, h, i, and j] of 1041 follicles) at termination of IM exposure (black bars) and after the 1-month depuration period 1042 (IMD) (gray bars). See the legend of Figure 2 for the abbreviation of follicular stages. Results 1043 that do not share the same letter are significantly different. $n=48$. IM: the sum of IM-1, IM-2 1044 and IM-3, IMD: the sum of IM-1, IM-2 and IM-3 after the one month depuration.

1046 Fig. 6. Sperm quality parameters in untreated (control) and IM-treated fish. Density, per mL, $1047(\mathrm{n}=35)(\mathrm{a})$ and motility $(\mathrm{n}=20)$ at different "seconds post activation", spa of sperm. Results 1048 that do not share the same letter are significantly different.

1050 Fig. 7. Density, per $\mathrm{mL},(\mathrm{n}=35)$ and motility $(\mathrm{n}=20)$ of sperm in relationship with the frequency of exposure to IM.

1052 
Table. 1. IM-induced changes in larval morphometric ratios.

\begin{tabular}{|c|c|c|c|c|c|}
\hline \multirow[t]{2}{*}{ No. } & \multirow[t]{2}{*}{ Variables } & \multicolumn{4}{|c|}{ IM exposure frequency } \\
\hline & & $\mathbf{0}$ & 1 & 2 & 3 \\
\hline 1 & BL/BD1-72 & $9.33 \pm 0.09^{\mathbf{b}}$ & $8.80 \pm 0.04^{\mathrm{a}}$ & $8.75 \pm 0.15^{\mathrm{a}}$ & $9.68 \pm 0.10^{\mathrm{c}}$ \\
\hline 2 & $\mathrm{APB} / \mathrm{BD} 1-72$ & $3.61 \pm 0.06^{\mathbf{b}}$ & $3.52 \pm 0.16^{\mathrm{bc}}$ & $3.33 \pm 0.11^{\mathrm{a}}$ & $3.74 \pm 0.11^{\mathrm{c}}$ \\
\hline 3 & $\mathrm{BL} / \mathrm{BD} 1-96$ & $10.23 \pm 0.09^{\mathbf{c}}$ & $9.71 \pm 0.11^{\mathrm{b}}$ & $9.60 \pm 0.22^{b}$ & $8.96 \pm 0.03^{\mathrm{a}}$ \\
\hline 4 & APB/BD1-96 & $3.96 \pm 0.05^{\mathbf{c}}$ & $3.70 \pm 0.14^{b}$ & $3.56 \pm 0.07^{\mathrm{a}}$ & $3.53 \pm 0.07^{\mathrm{a}}$ \\
\hline 5 & APB/BD2-96 & $2.53 \pm 0.06^{\mathbf{c}}$ & $2.36 \pm 0.07^{\mathbf{b}}$ & $2.32 \pm 0.05^{\mathrm{ab}}$ & $2.25 \pm 0.01^{\mathrm{a}}$ \\
\hline 6 & $\mathrm{BL} / \mathrm{BD} 1-120$ & $11.70 \pm 0.58^{d}$ & $10.13 \pm 0.22^{\mathrm{a}}$ & $10.04 \pm 0.14^{\mathrm{a}}$ & $10.83 \pm 0.15^{\mathbf{b}}$ \\
\hline 7 & BL/APB-120 & $2.67 \pm 0.05^{\text {bc }}$ & $2.63 \pm 0.08^{\mathrm{ab}}$ & $2.56 \pm 0.05^{\mathrm{a}}$ & $2.72 \pm 0.04^{c}$ \\
\hline 8 & $\mathrm{BL} / \mathrm{BD} 2-120$ & $7.16 \pm 0.24^{\mathrm{d}}$ & $6.18 \pm 0.45^{\mathrm{a}}$ & $6.44 \pm 0.11^{\mathrm{ab}}$ & $6.68 \pm 0.10^{b}$ \\
\hline 9 & $\mathrm{BL} / \mathrm{HL}-120$ & $3.77 \pm 0.11^{\mathrm{a}}$ & $3.72 \pm 0.05^{\mathrm{a}}$ & $3.81 \pm 0.11^{\mathrm{a}}$ & $4.03 \pm 0.05^{\mathrm{b}}$ \\
\hline 10 & $\mathrm{PoPB} / \mathrm{BD} 2-120$ & $4.48 \pm 0.13^{\mathrm{b}}$ & $3.84 \pm 0.34^{\mathrm{a}}$ & $3.92 \pm 0.16^{\mathbf{a}}$ & $4.24 \pm 0.03^{b}$ \\
\hline 11 & $\mathrm{BD} 2 / \mathrm{HL}-120$ & $0.53 \pm 0.02^{\mathrm{a}}$ & $0.60 \pm 0.04^{b}$ & $0.59 \pm 0.01^{b}$ & $0.59 \pm 0.02^{b}$ \\
\hline 12 & $\mathrm{BL} / \mathrm{BD} 1-144$ & $11.65 \pm 0.15^{\mathbf{c}}$ & $10.29 \pm 0.47^{\mathrm{a}}$ & $10.61 \pm 0.17^{\mathrm{a}}$ & $11.02 \pm 0.11^{\mathrm{b}}$ \\
\hline 13 & $\mathrm{BL} / \mathrm{BD} 2-144$ & $7.02 \pm 0.25^{\mathrm{b}}$ & $6.58 \pm 0.28^{\mathrm{a}}$ & $6.92 \pm 0.09^{\mathbf{b}}$ & $7.08 \pm 0.07^{\mathbf{b}}$ \\
\hline 14 & PoPB/BD1-144 & $7.47 \pm 0.08^{c}$ & $6.55 \pm 0.14^{\mathrm{a}}$ & $6.87 \pm 0.38^{\mathrm{ab}}$ & $6.97 \pm 0.18^{b}$ \\
\hline 15 & $\mathrm{BD} 1 / \mathrm{BD} 2-144$ & $0.60 \pm 0.01^{\mathrm{a}}$ & $0.64 \pm 0.01^{\mathrm{b}}$ & $0.65 \pm 0.02^{b}$ & $0.64 \pm 0.02^{b}$ \\
\hline 16 & BD1/HL-144 & $0.32 \pm 0.02^{(\mathrm{a}}$ & $0.36 \pm 0.02^{\mathbf{b}}$ & $0.35 \pm 0.02^{\mathrm{b}}$ & $0.35 \pm 0.01^{\mathrm{ab}}$ \\
\hline 17 & BL/HL-168 & $3.74 \pm 0.10^{\mathrm{a}}$ & $4.03 \pm 0.04^{\mathfrak{c}}$ & $3.87 \pm 0.03^{\mathrm{b}}$ & $3.69 \pm 0.07^{\mathrm{a}}$ \\
\hline 18 & $\mathrm{BL} / \mathrm{BD} 1-168$ & $10.59 \pm 0.67^{\mathrm{a}}$ & $11.32 \pm 0.08^{\mathbf{b}}$ & $11.47 \pm 0.12^{b}$ & $11.27 \pm 0.07^{\mathbf{b}}$ \\
\hline 19 & APB/HL-168 & $1.36 \pm 0.09^{\mathrm{ab}}$ & $1.47 \pm 0.08^{\mathbf{b}}$ & $1.44 \pm 0.06^{\mathbf{a b}}$ & $1.35 \pm 0.04^{\mathrm{a}}$ \\
\hline 20 & BL/BD1-192 & $12.10 \pm 0.33^{\mathbf{c}}$ & $11.05 \pm 0.31^{\mathrm{a}}$ & $11.61 \pm 0.11^{b}$ & $12.06 \pm 0.06^{\mathbf{c}}$ \\
\hline 21 & APB/BD1-192 & $4.34 \pm 0.08^{b}$ & $4.07 \pm 0.04^{\mathrm{a}}$ & $4.00 \pm 0.04^{\mathrm{a}}$ & $4.36 \pm 0.14^{\mathrm{b}}$ \\
\hline 22 & APB/BD2-192 & $2.57 \pm 0.05^{\mathbf{b}}$ & $2.47 \pm 0.08^{\mathrm{a}}$ & $2.40 \pm 0.04^{\mathrm{a}}$ & $2.69 \pm 0.05^{\mathrm{b}}$ \\
\hline 23 & $\mathrm{BL} / \mathrm{BD} 1-216$ & $12.64 \pm 0.40^{\mathbf{b}}$ & $11.75 \pm 0.22^{\mathrm{a}}$ & $11.47 \pm 0.29^{a}$ & $12.60 \pm 0.13^{b}$ \\
\hline 24 & BL/HL-240 & $3.76 \pm 0.06^{\mathrm{a}}$ & $3.78 \pm 0.04^{\mathrm{a}}$ & $4.06 \pm 0.01^{\mathrm{b}}$ & $4.08 \pm 0.01^{\mathrm{b}}$ \\
\hline 25 & $\mathrm{BL} / \mathrm{BD} 1-240$ & $11.48 \pm 0.21^{\mathrm{a}}$ & $11.76 \pm 0.79^{\mathrm{ab}}$ & $12.22 \pm 0.29^{b}$ & $13.29 \pm 0.15^{\mathrm{c}}$ \\
\hline 26 & PoPB/BD1-240 & $7.14 \pm 0.13^{\mathrm{a}}$ & $7.59 \pm 0.43^{\mathbf{b}}$ & $7.83 \pm 0.04^{b}$ & $8.30 \pm 0.14^{\mathrm{c}}$ \\
\hline
\end{tabular}

Values superscripted with the same letter are not significantly different. $\mathrm{n}=5$ (for each treatment). See the legend of Figure 1 for abbreviations of the morphometric ratios. 
Table 2. IM exposure frequency effect on larval morphometric ratios. Regression equations, correlation $\left(r^{2}\right)$, and $\mathrm{F}$ values of the significant relationships found between the larval morphometric ratios and the frequency of exposure of adult zebrafish to IM-0, IM-1, IM-2, and IM-3.

\begin{tabular}{|c|c|c|c|c|}
\hline \multirow[t]{2}{*}{ No. } & Variables & \multirow[t]{2}{*}{ Equation } & \multirow[t]{2}{*}{$r^{2}$} & \multirow[t]{2}{*}{$\mathbf{F}$} \\
\hline & Independent & & & \\
\hline$\underline{1}$ & BL/BD1-72 & $y=0.365 x^{2}-0.995 x+9.354$ & $\underline{0.933}$ & $\underline{90.440}$ \\
\hline$\frac{1}{2}$ & $\mathrm{IPB} / \mathrm{BD} 1-72$ & $y=0.018 x+3.522$ & 0.013 & 0.183 \\
\hline 3 & BL/BD1-96 & $y=-0.392 x+10.213$ & 0.881 & 103.998 \\
\hline 4 & IPB/BD1-96 & $y=-0.144 x+3.901$ & 0.742 & 40.186 \\
\hline 5 & IPB/BD2-96 & $y=-0.088 x+2.497$ & 0.758 & 43.787 \\
\hline 6 & $\underline{\mathrm{BL} / \mathrm{BD} 1-120}$ & $y=0.591 x^{2}-2.046 x+11.672$ & 0.839 & 33.842 \\
\hline 7 & $\mathrm{BL} / \mathrm{IPB}-120$ & $y=0.010 x+2.630$ & 0.021 & 0.299 \\
\hline$\underline{8}$ & $\mathrm{BL} / \mathrm{BD} 2-120$ & $y=0.306 x^{2}-1.038 x+7.097$ & $\underline{0.609}$ & $\underline{10.132}$ \\
\hline 9 & BL/HL-120 & $y=0.090 x+3.696$ & 0.491 & 13.490 \\
\hline$\underline{10}$ & PoPB/BD2-120 & $y=0.241 x^{2}-0.788 x+4.453$ & 0.665 & 12.912 \\
\hline$\underline{11}$ & BD2/HL-120 & $y=-0.020 x^{2}+0.077 x+0.532$ & $\underline{0.600}$ & 9.750 \\
\hline$\overline{12}$ & $\overline{\mathrm{BL} / \mathrm{BD} 1-144}$ & $y=0.443 x^{2}-1.484 x+11.568$ & $\overline{0.726}$ & $\overline{17.263}$ \\
\hline 13 & $\overline{\mathrm{BL} / \mathrm{BD} 2-144}$ & $y=0.051 x+6.820$ & $\overline{0.050}$ & 0.743 \\
\hline 14 & PoPB/BD1-144 & $y=-0.116 x+7.139$ & 0.114 & 1.809 \\
\hline$\underline{15}$ & $\underline{B D 1 / B D 2-144}$ & $y=-0.012 x^{2}+0.049 x+0.603$ & $\underline{0.620}$ & $\underline{10.600}$ \\
\hline 16 & BD1/HL-144 & $y=0.007 x+0.335$ & 0.120 & 1.901 \\
\hline 17 & BL/HL-168 & $y=-0.117 x^{2}+0.321 x+3.757$ & $\underline{0.723}$ & $\underline{17.006}$ \\
\hline$\overline{18}$ & $\overline{\mathrm{BL} / \mathrm{BD} 1-168}$ & $y=0.217 x+10.835$ & $\overline{0.290}$ & 5.707 \\
\hline 19 & IPB/HL-168 & $y=-0.008 x+1.415$ & 0.015 & 0.213 \\
\hline$\underline{20}$ & $\underline{B L / B D 1-192}$ & $y=0.376 x^{2}-1.081 x+12.013$ & $\underline{0.650}$ & 12.098 \\
\hline$\overline{21}$ & $\overline{\mathrm{IPB} / \mathrm{BD} 1-192}$ & $y=0.157 x^{2}-0.471 x+4.348$ & 0.799 & $\overline{25.857}$ \\
\hline$\underline{22}$ & IPB/BD2-192 & $y=0.097 x^{2}-0.263 x+2.581$ & $\underline{0.074}$ & $\underline{18.429}$ \\
\hline$\underline{23}$ & $\underline{\mathrm{BL} / \mathrm{BD} 1-216}$ & $y=0.505 x^{2}-1.555 x+12.677$ & $\frac{.071}{0.798}$ & $\frac{10.72}{25.745}$ \\
\hline$\overline{24}$ & BL/HL-240 & $y=0.122 x+3.738$ & 0.813 & $\overline{61.022}$ \\
\hline 25 & BL/BD1-240 & $y=0.587 x+11.309$ & 0.699 & 32.584 \\
\hline 26 & PoPB/BD1-240 & $y=0.371 x+7.159$ & 0.798 & 55.337 \\
\hline
\end{tabular}

See figure 1 legend for morphometric ratio abbreviations. Number of specimens $=20$. 


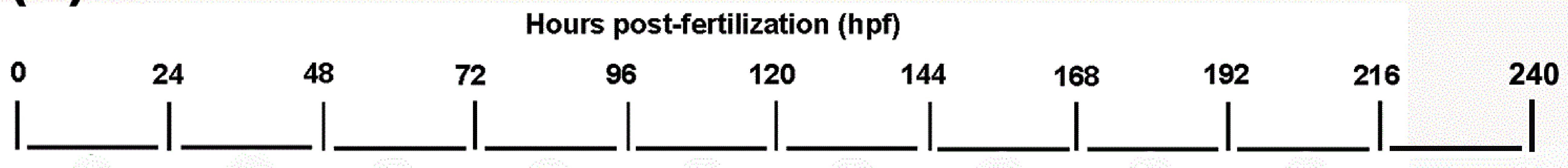

(b)

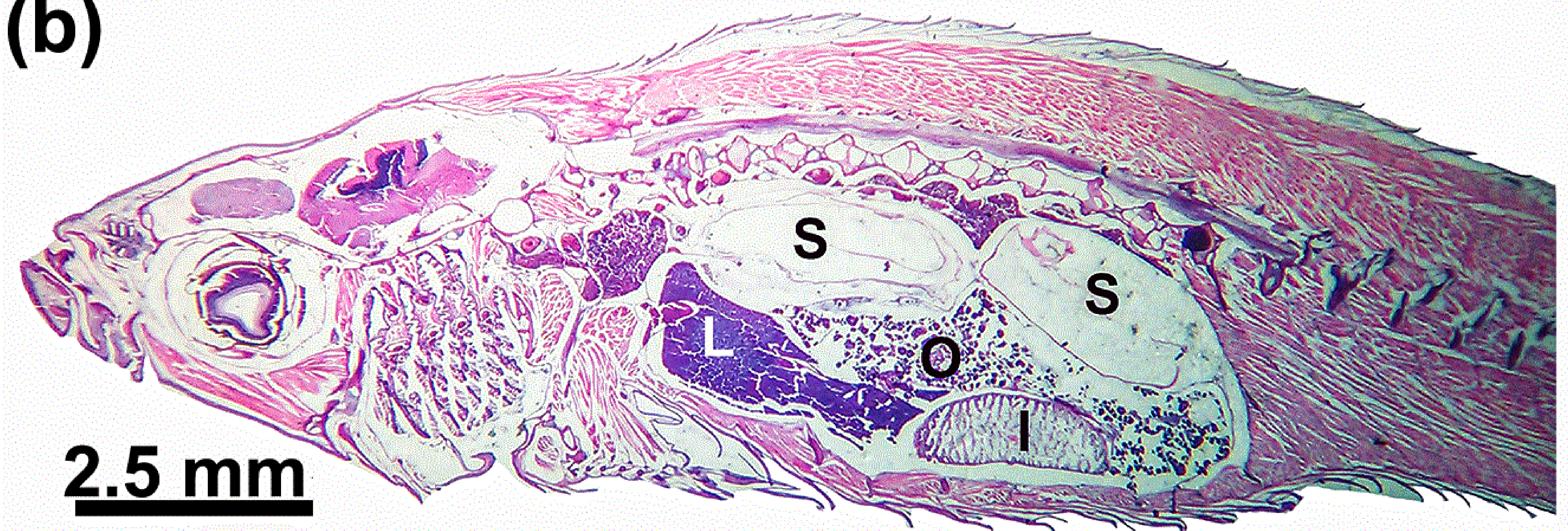

(c)

(d)

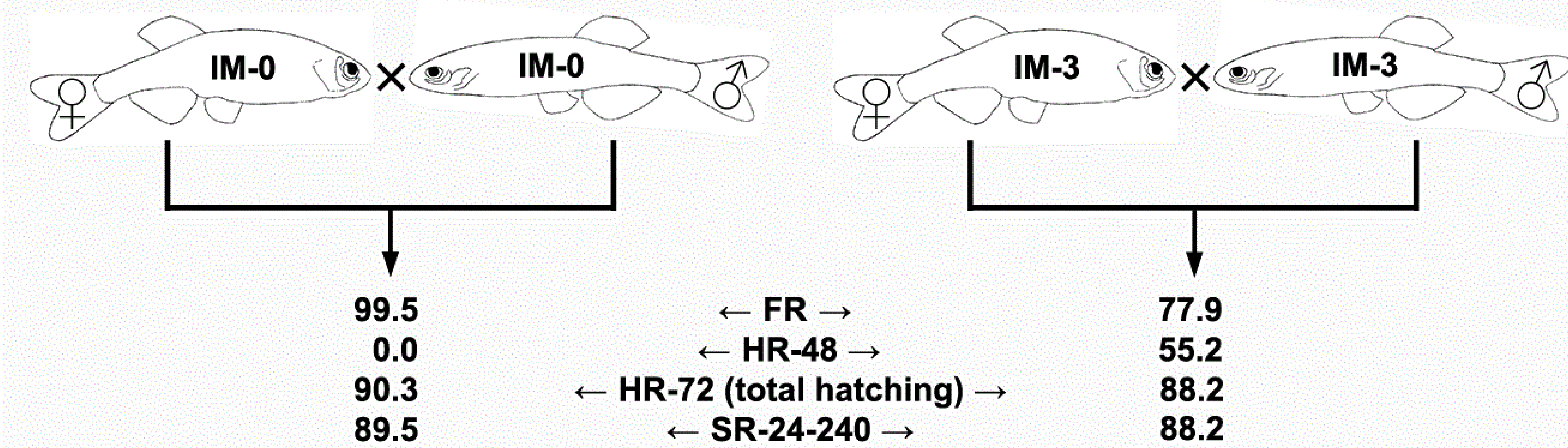

(e)

(f)

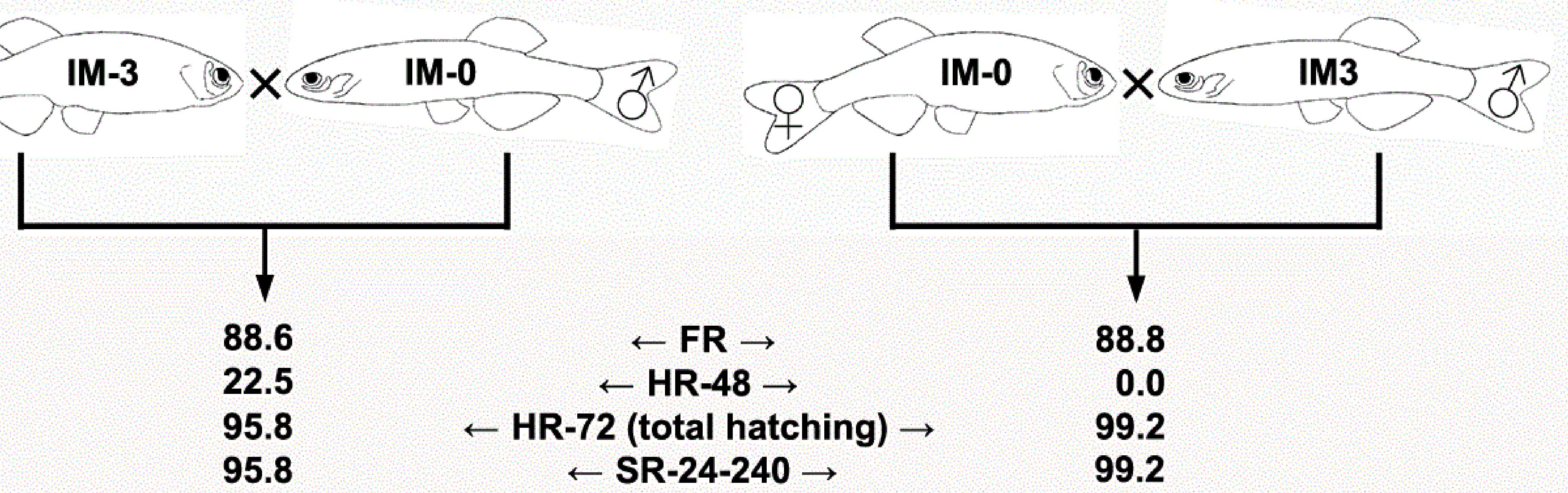

(g)

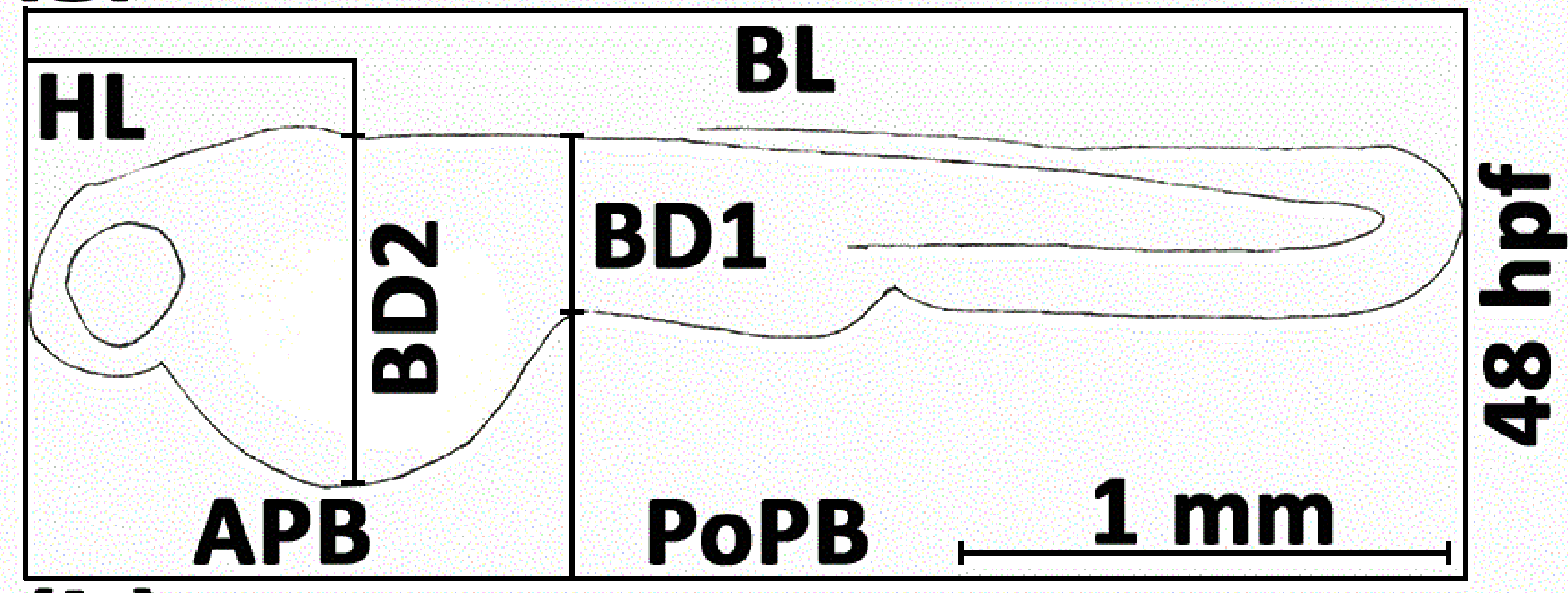

(h)

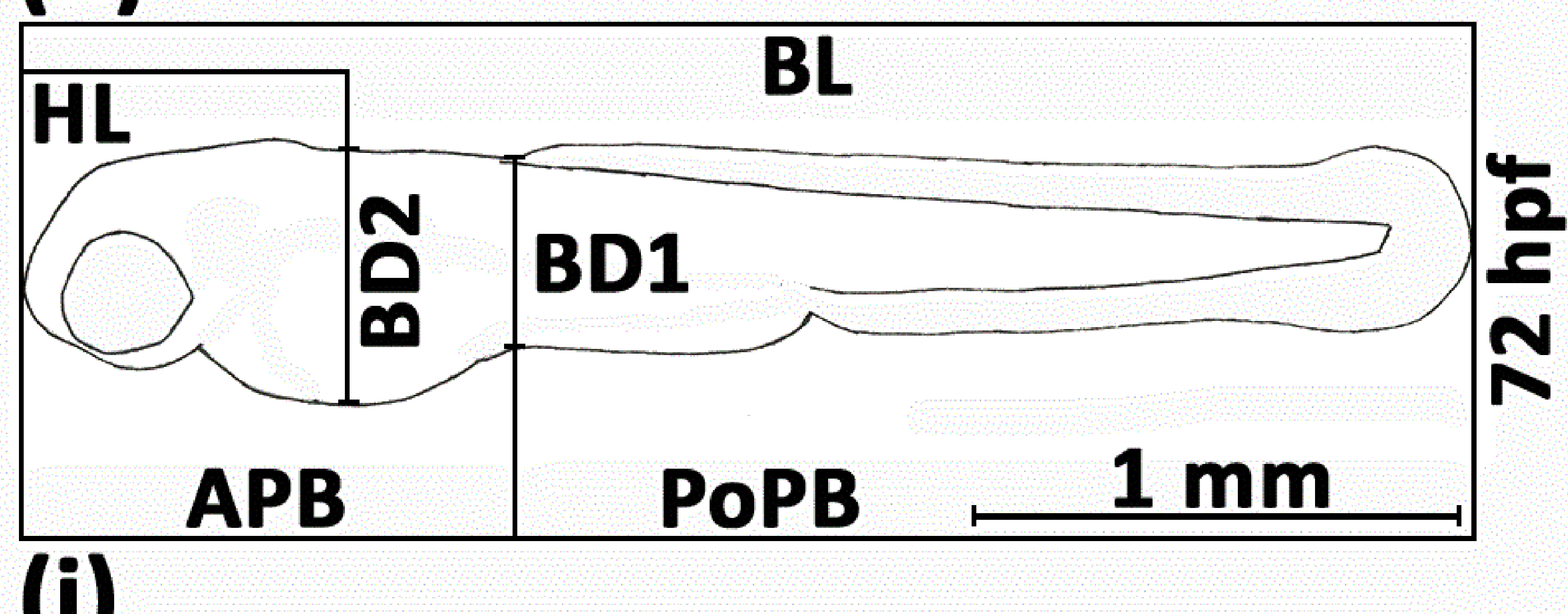

(i)

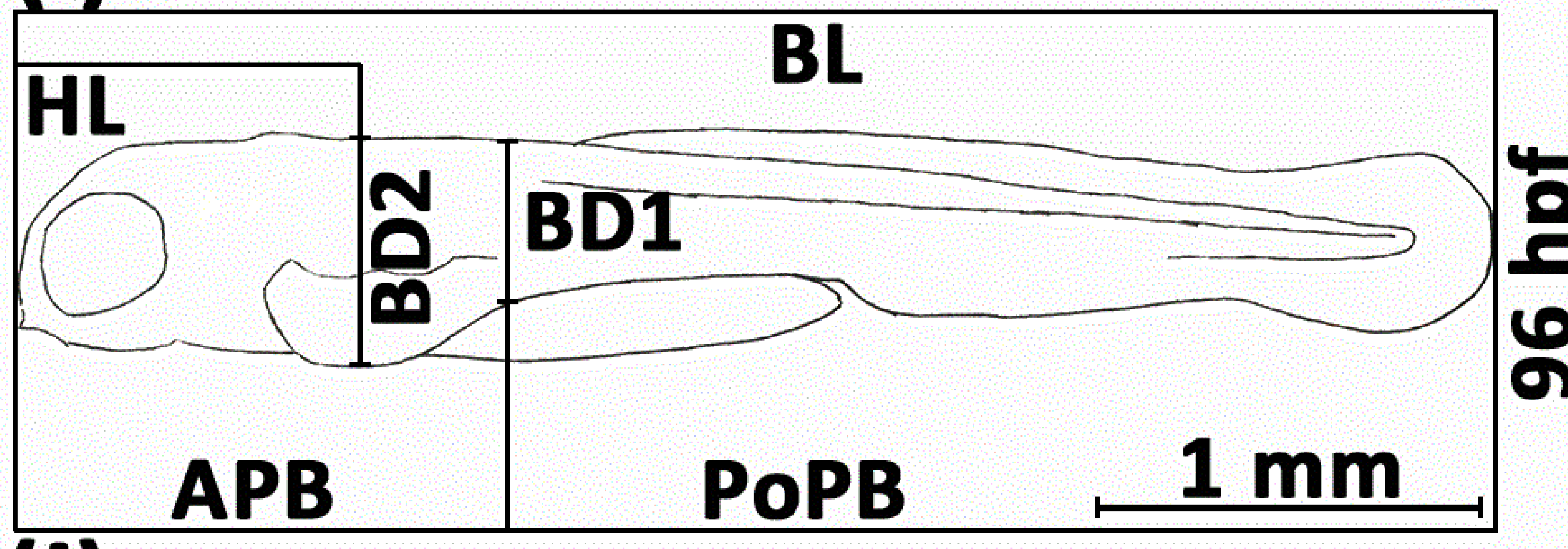

(j)

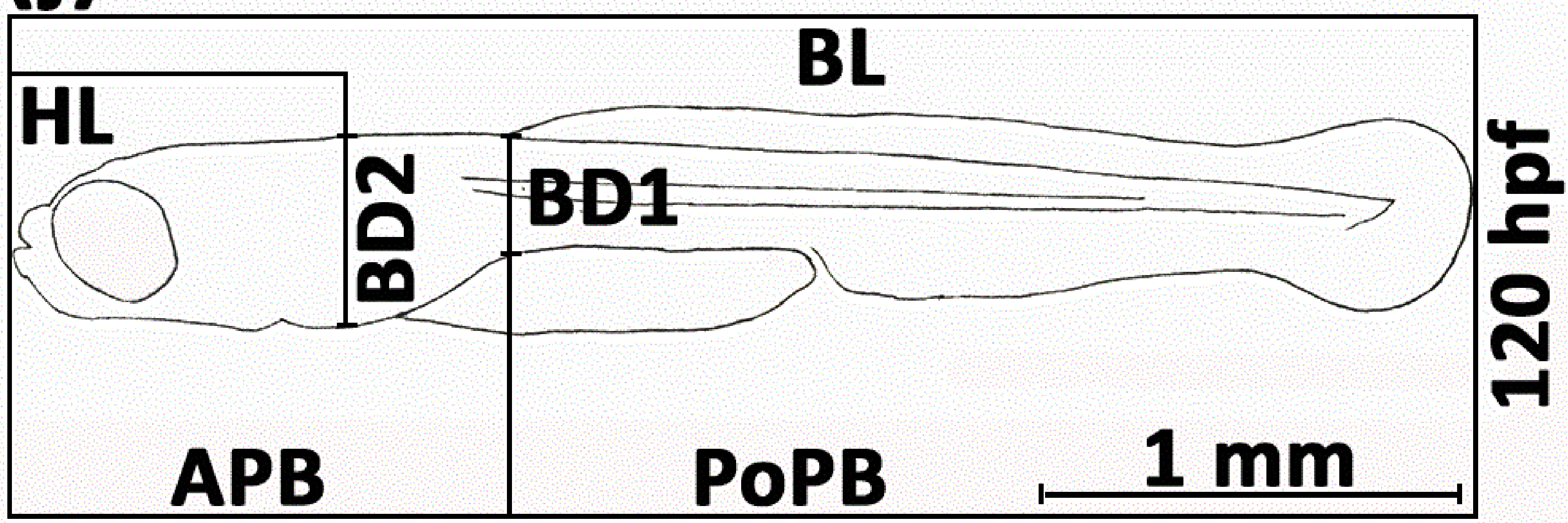









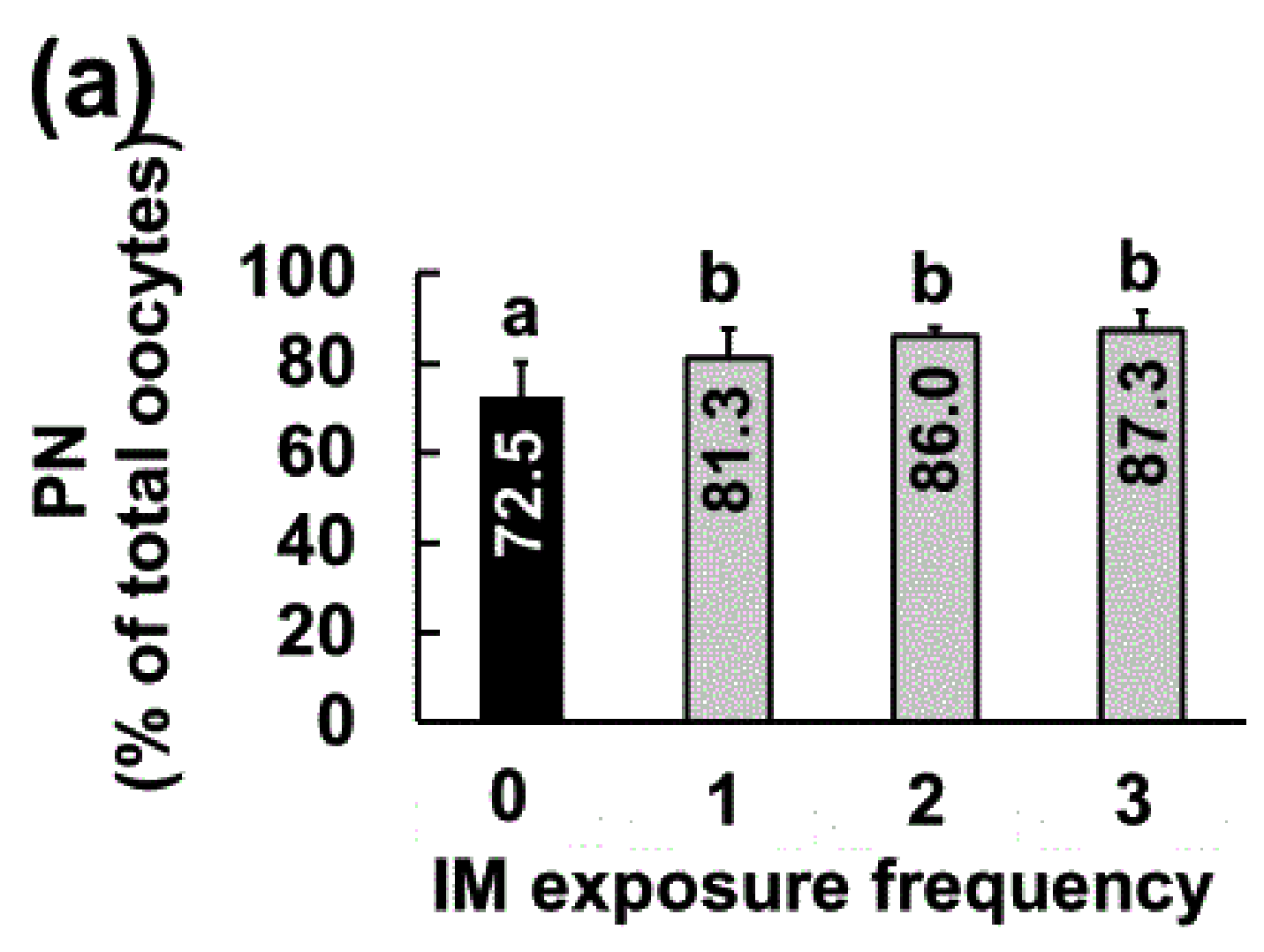

(d)

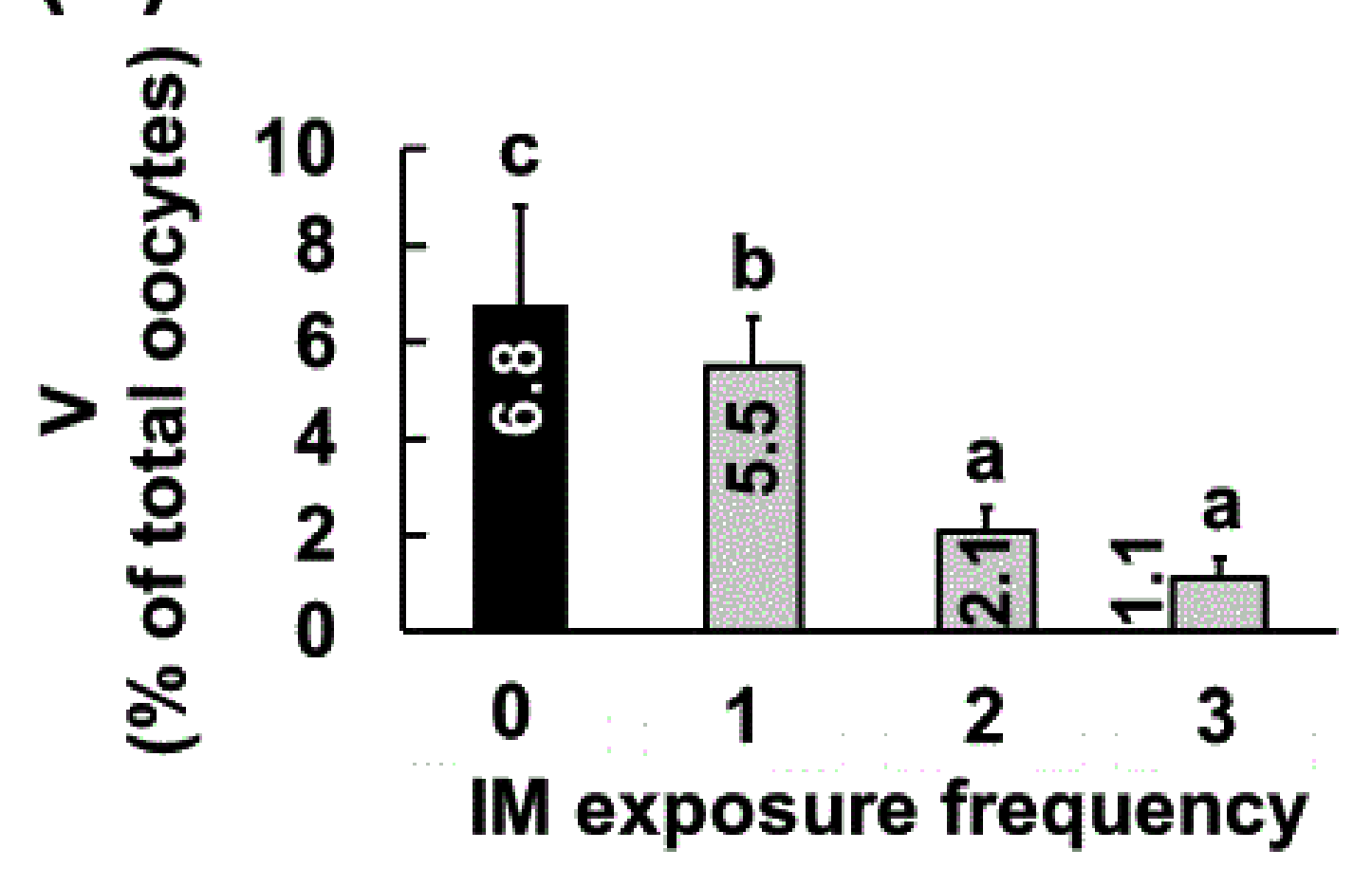

(g)

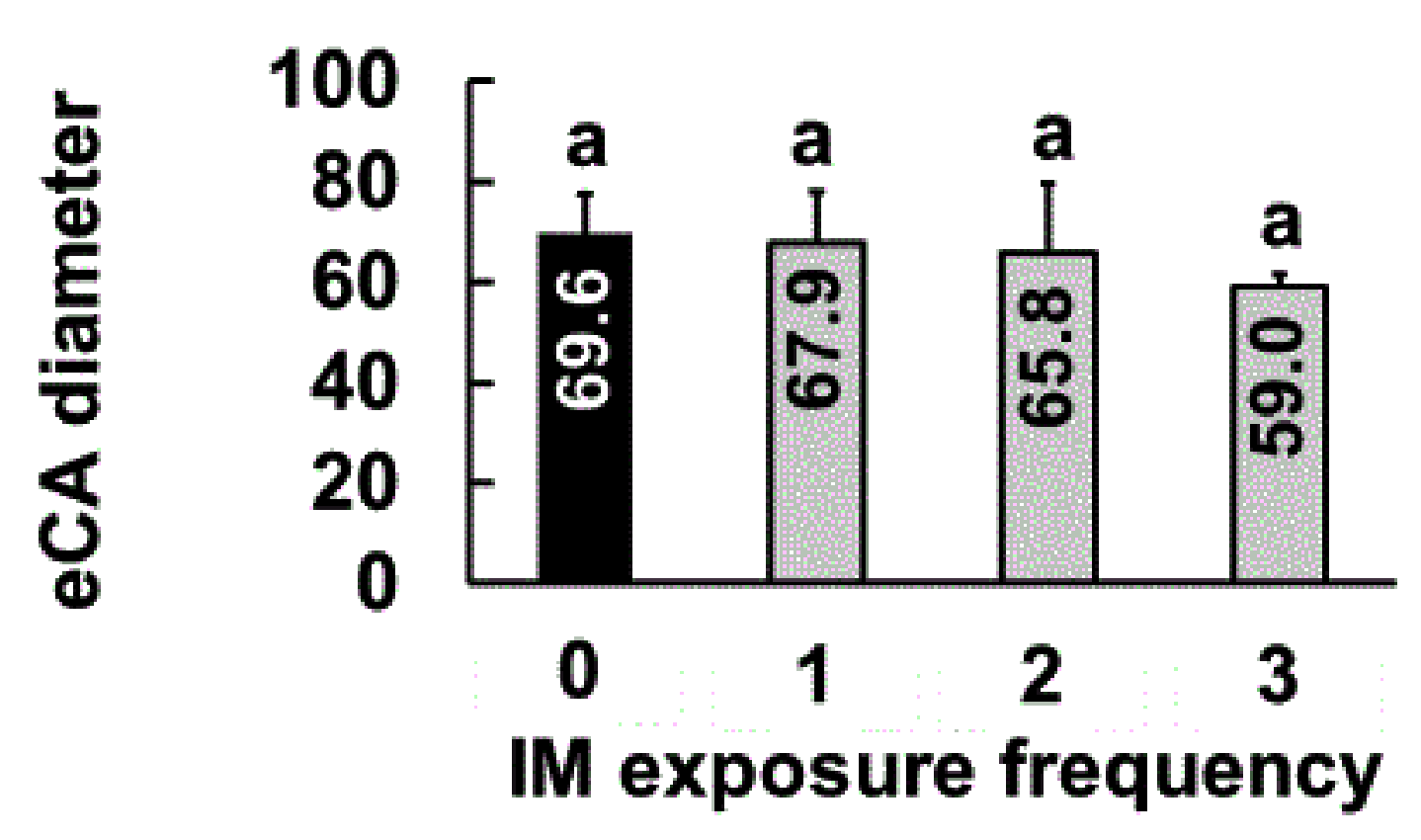

(j)

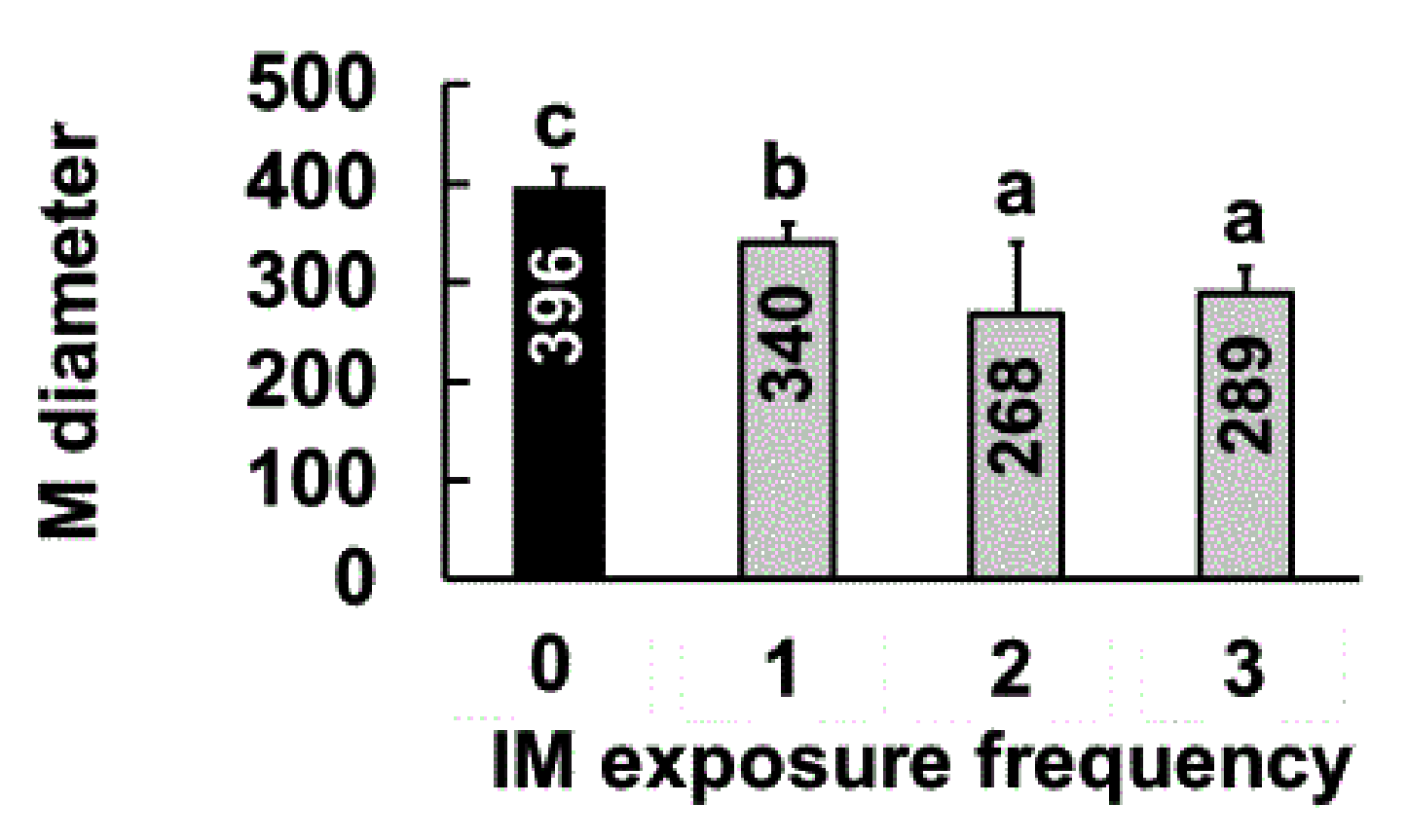

(b)

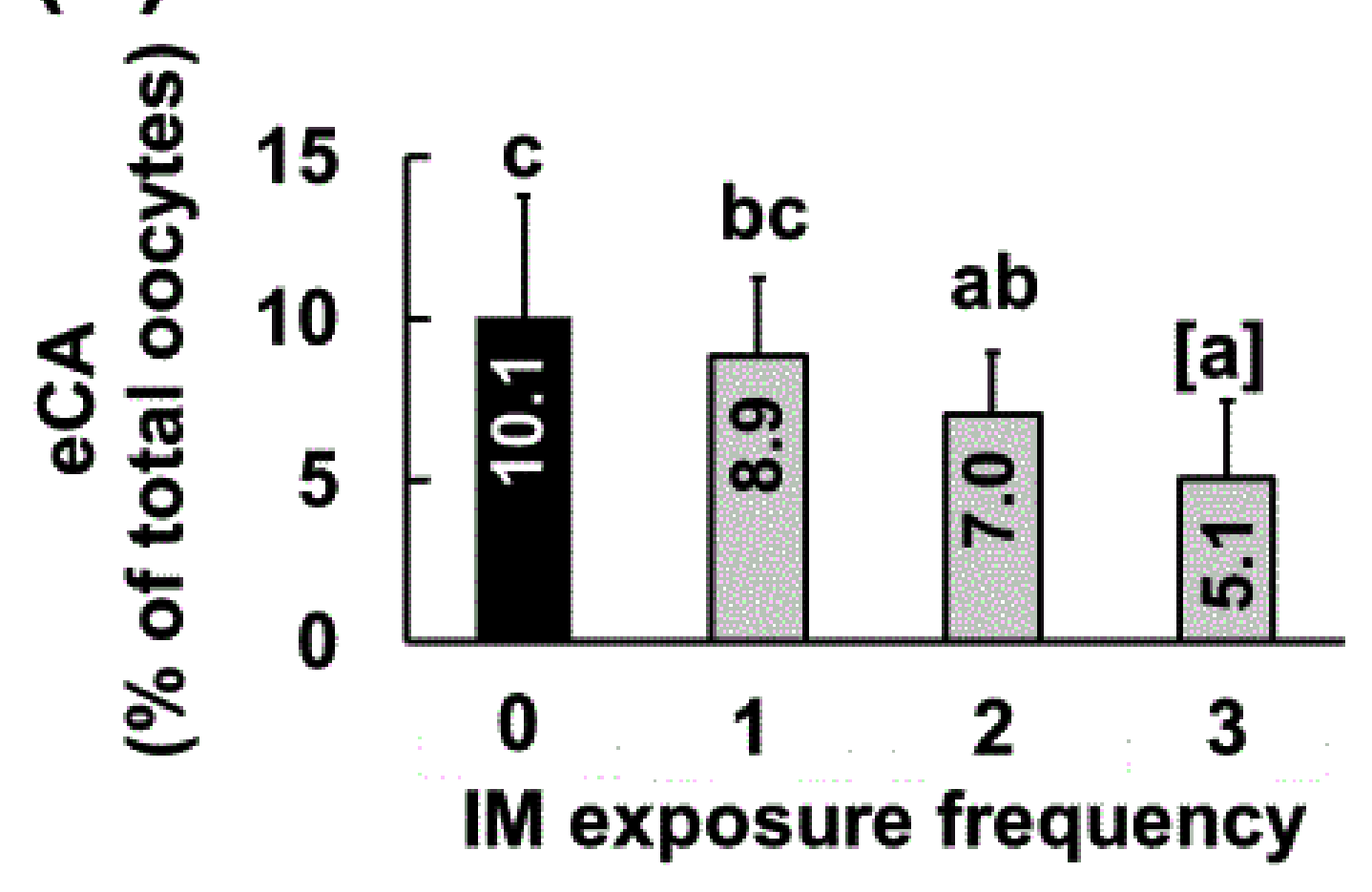

(e)

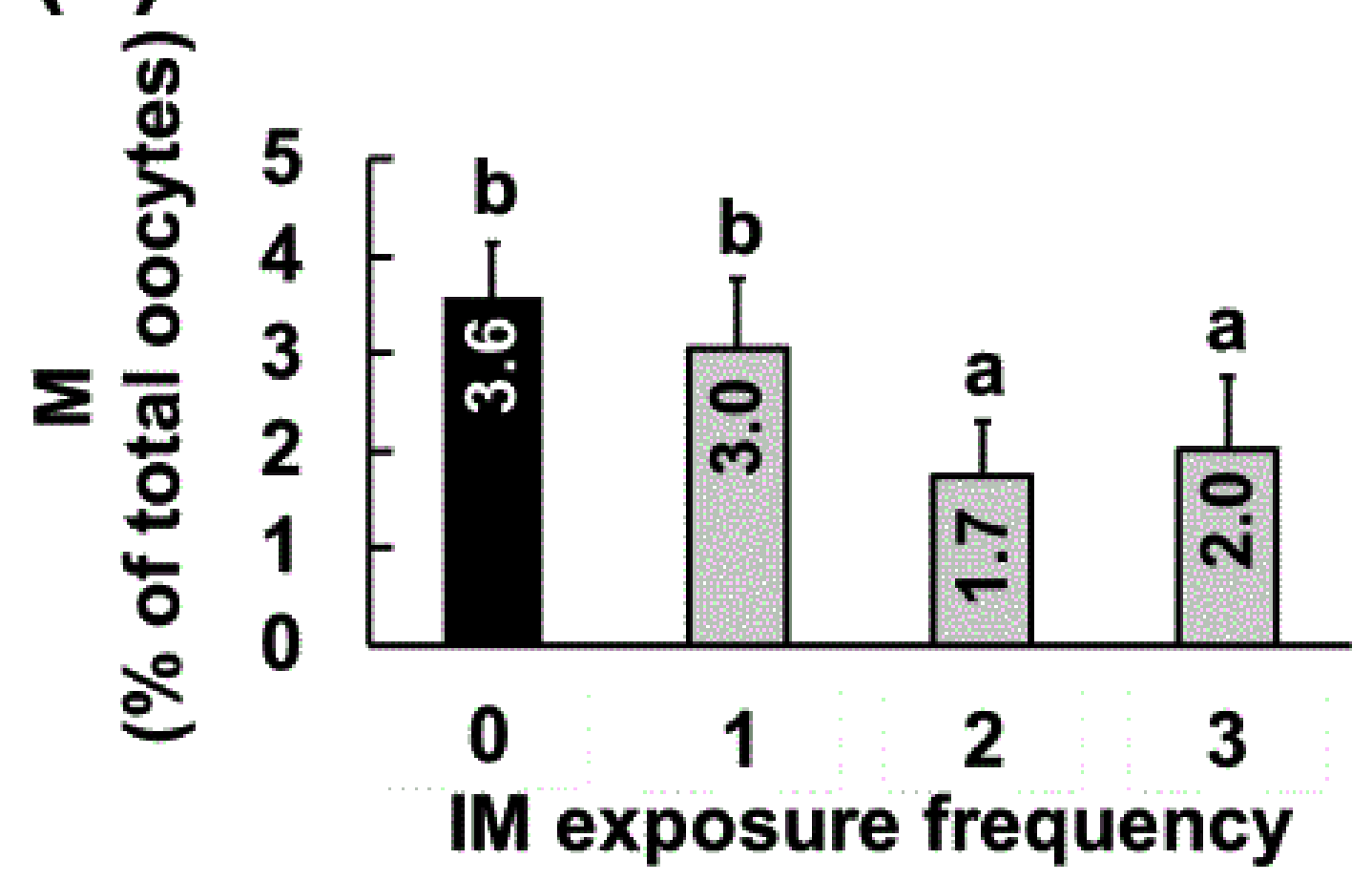

(h)

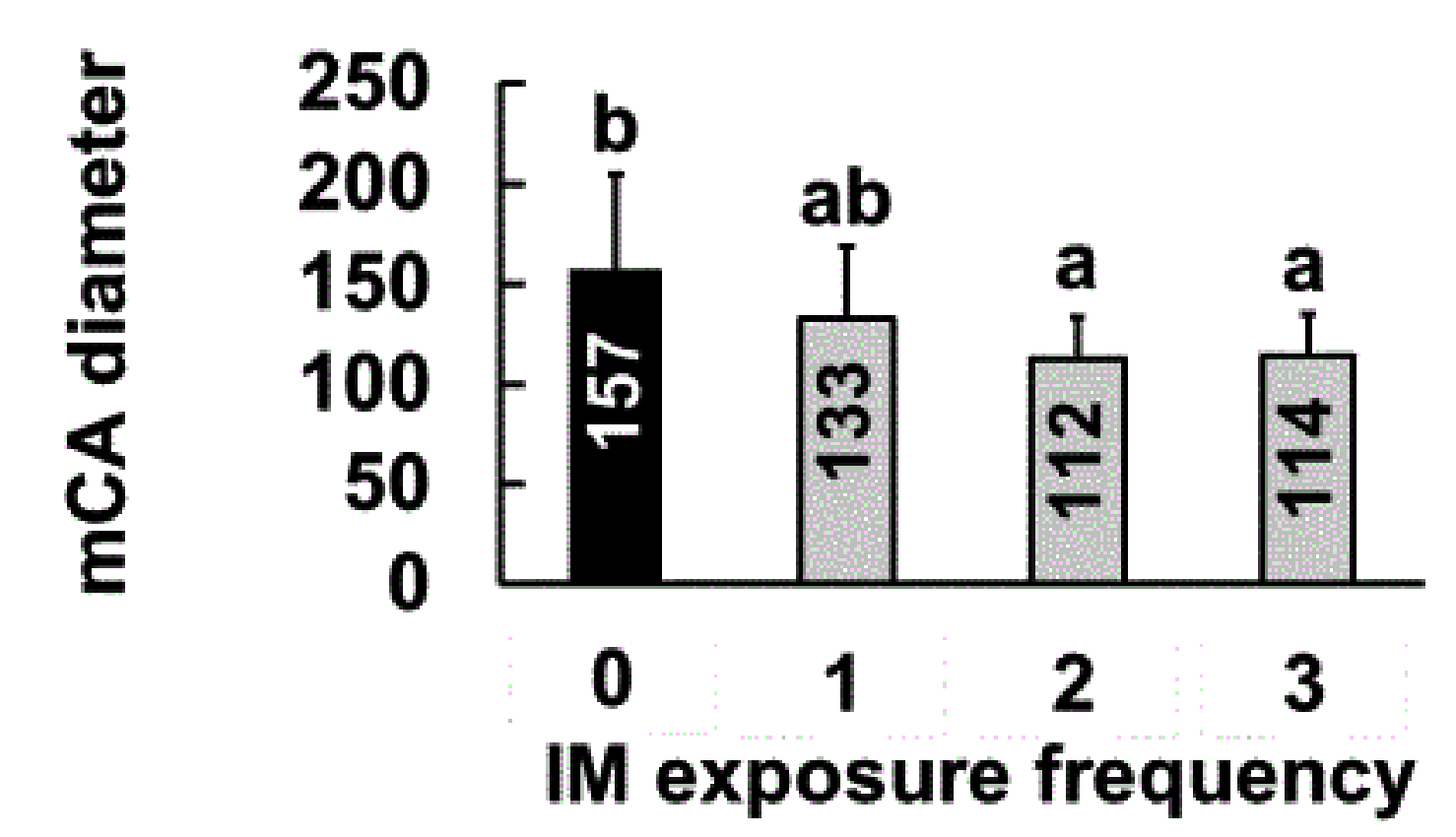

(c)

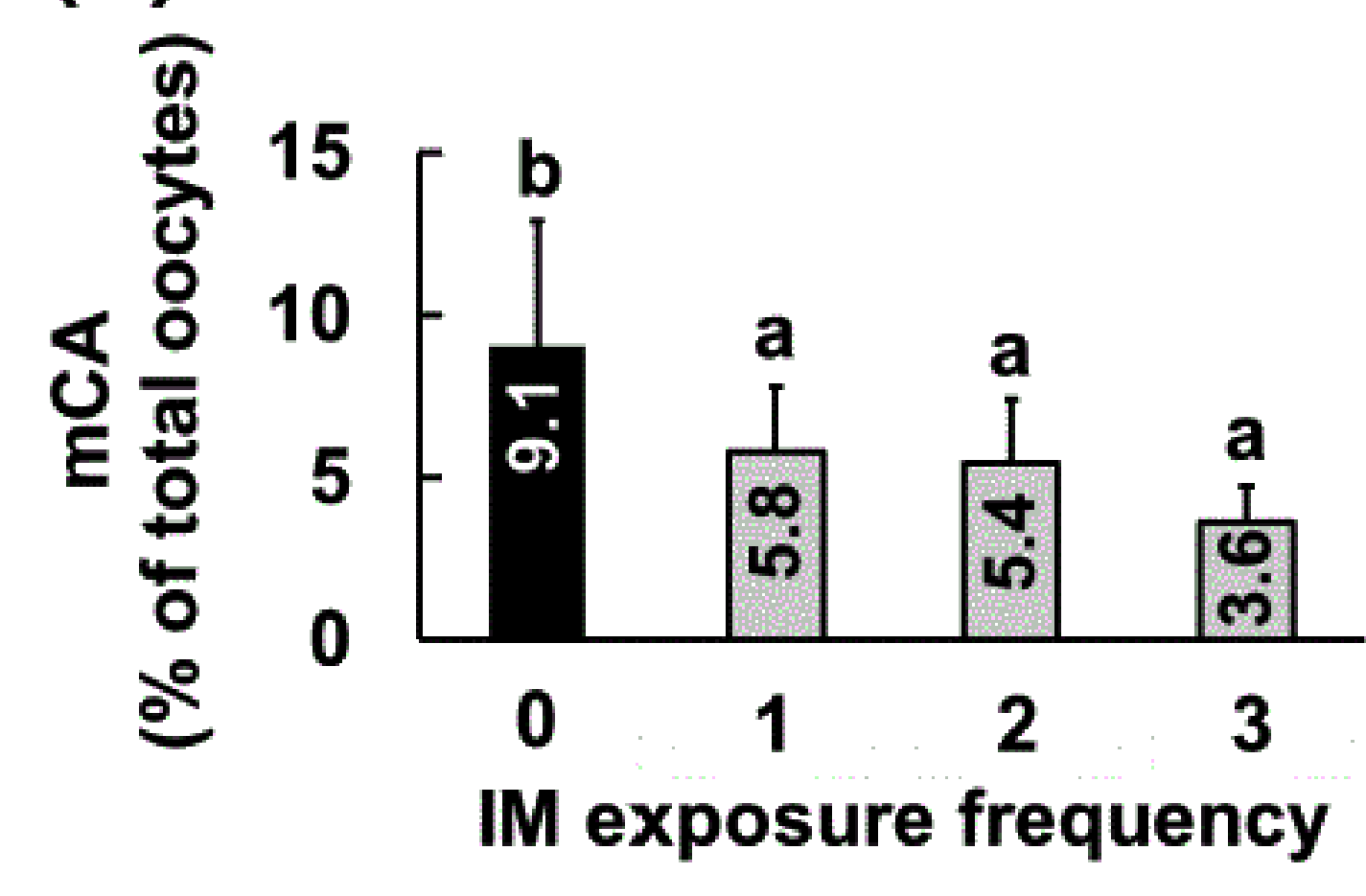

(f)

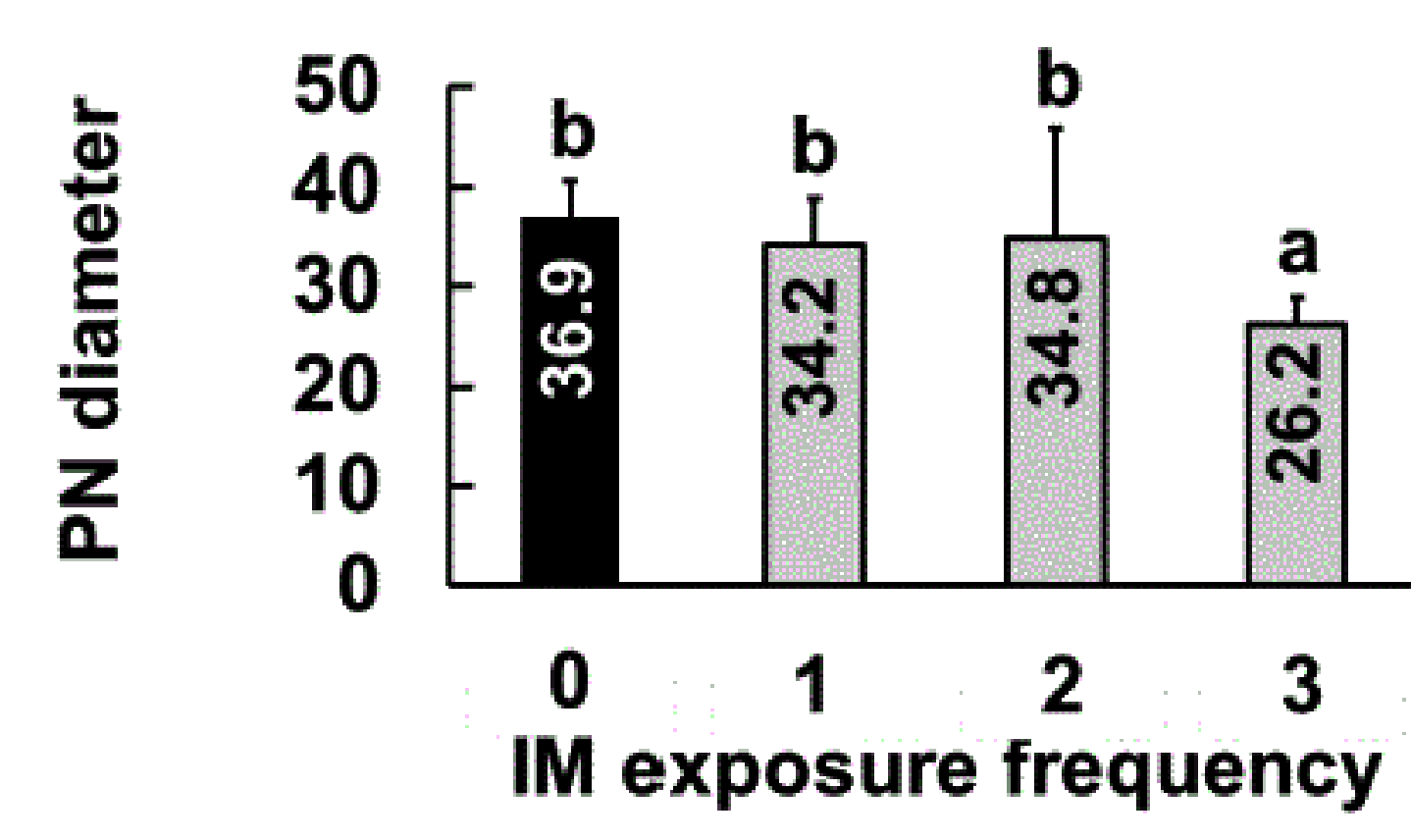

(i)

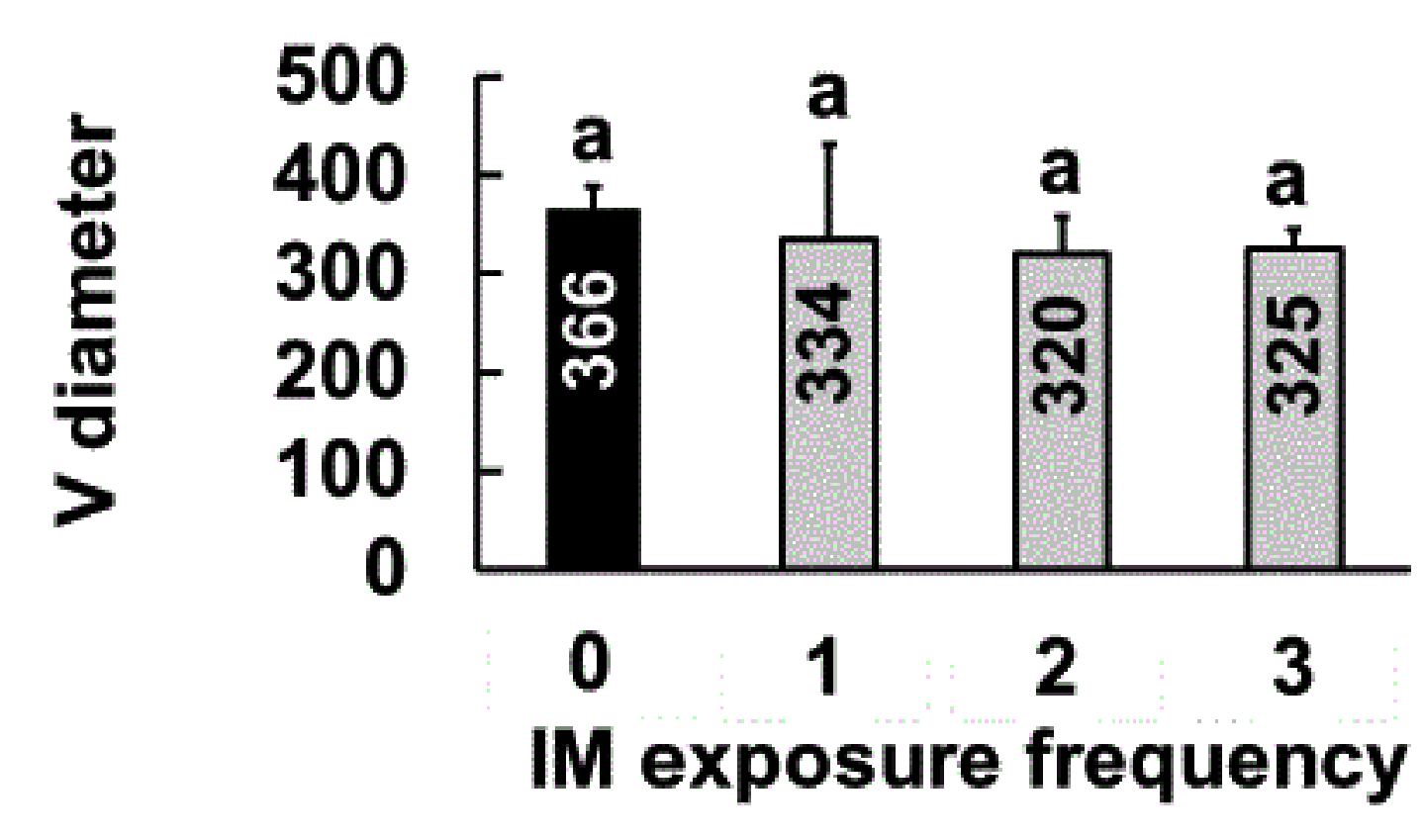




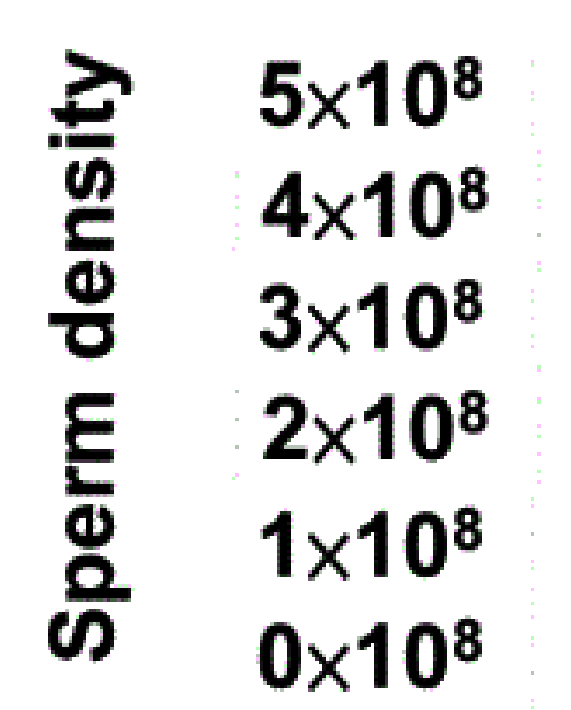

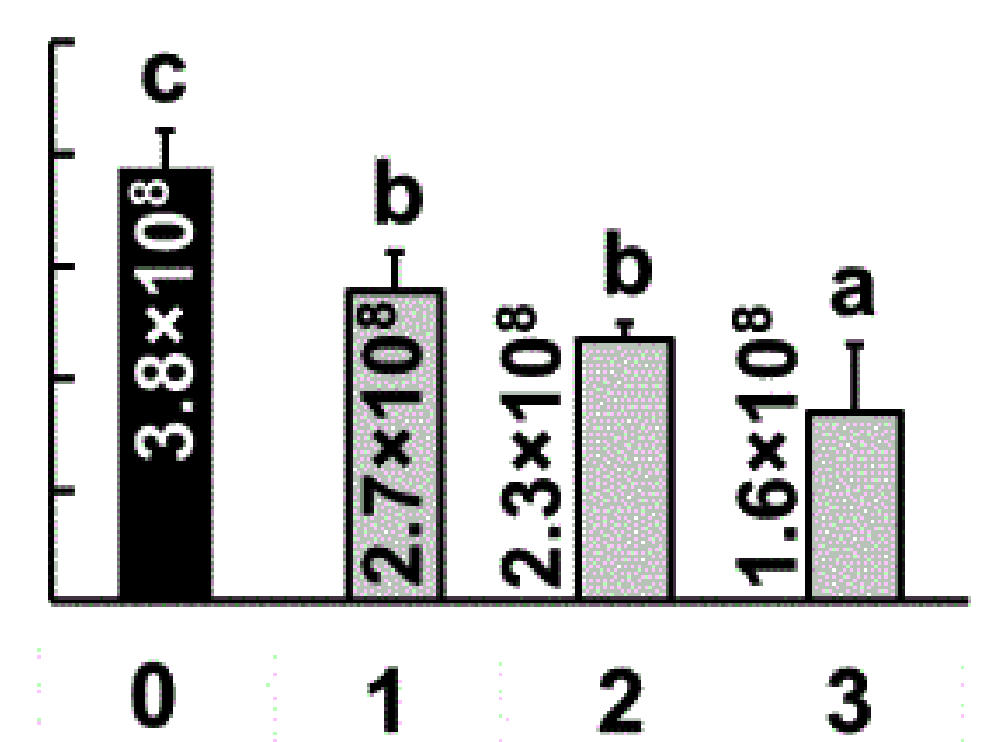

IM exposure frequency

(d)

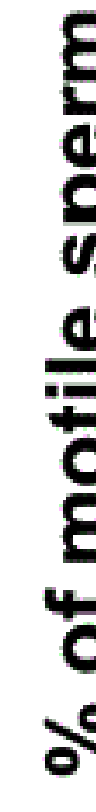

(g)

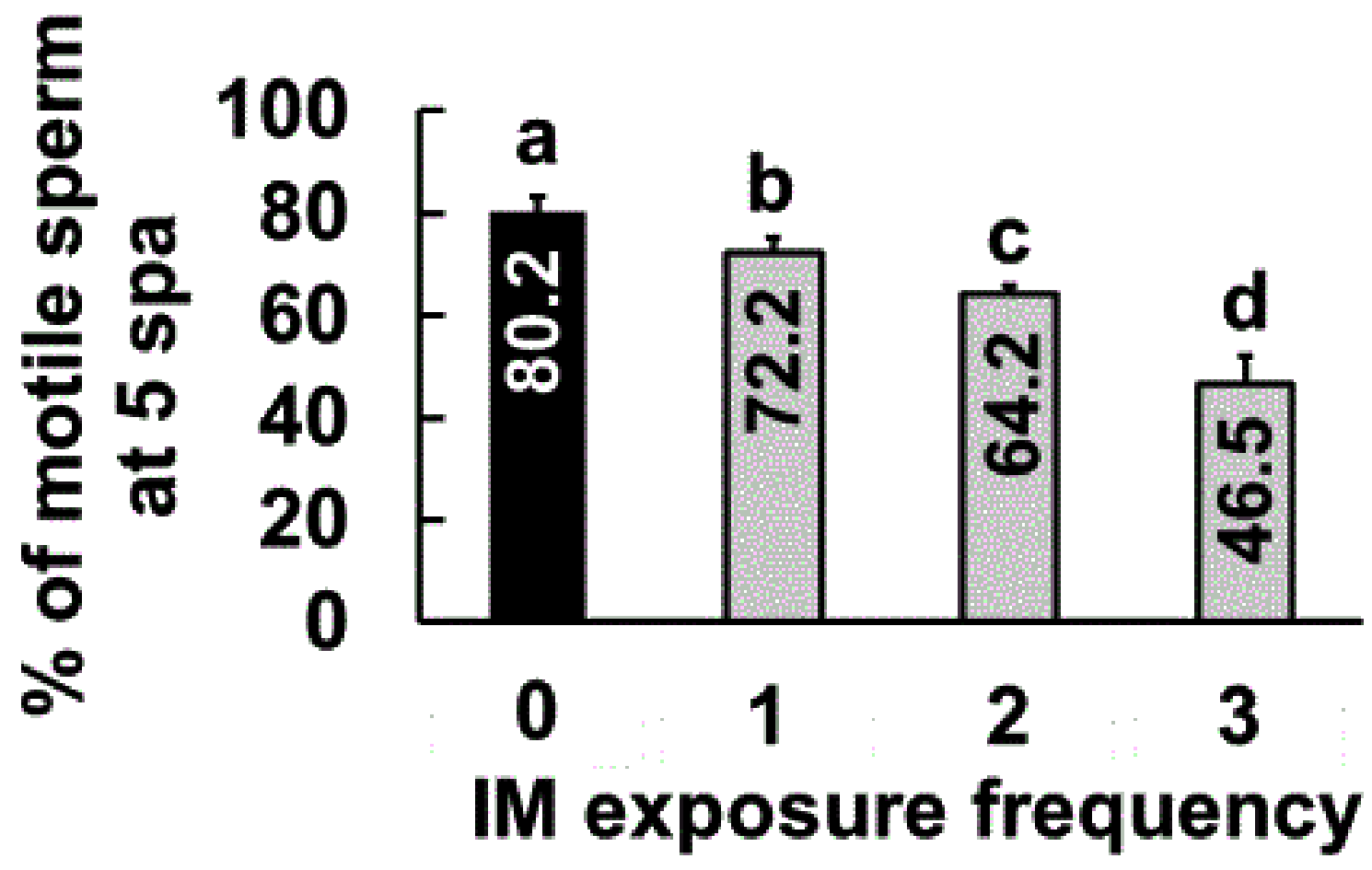

(e)

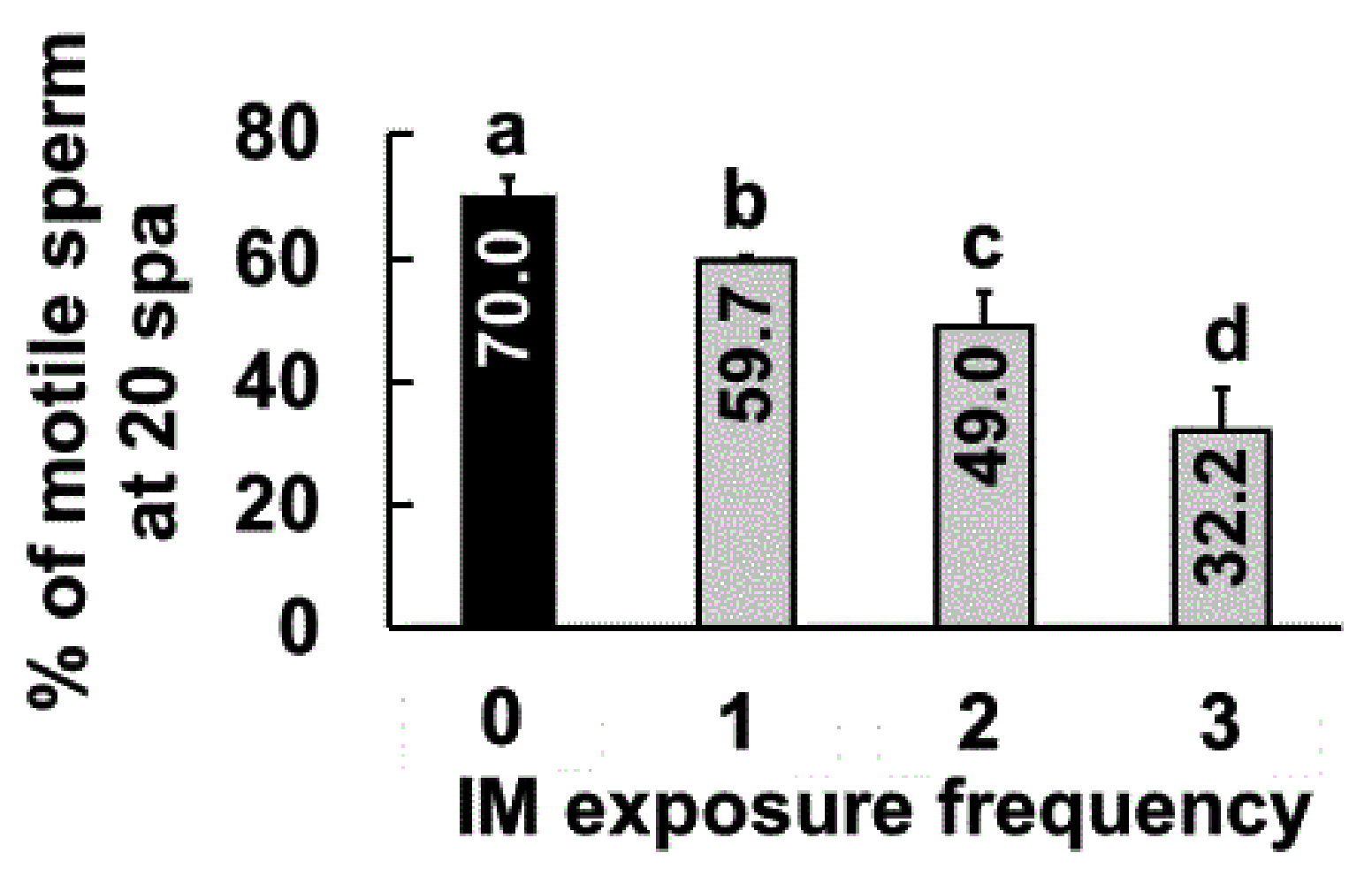

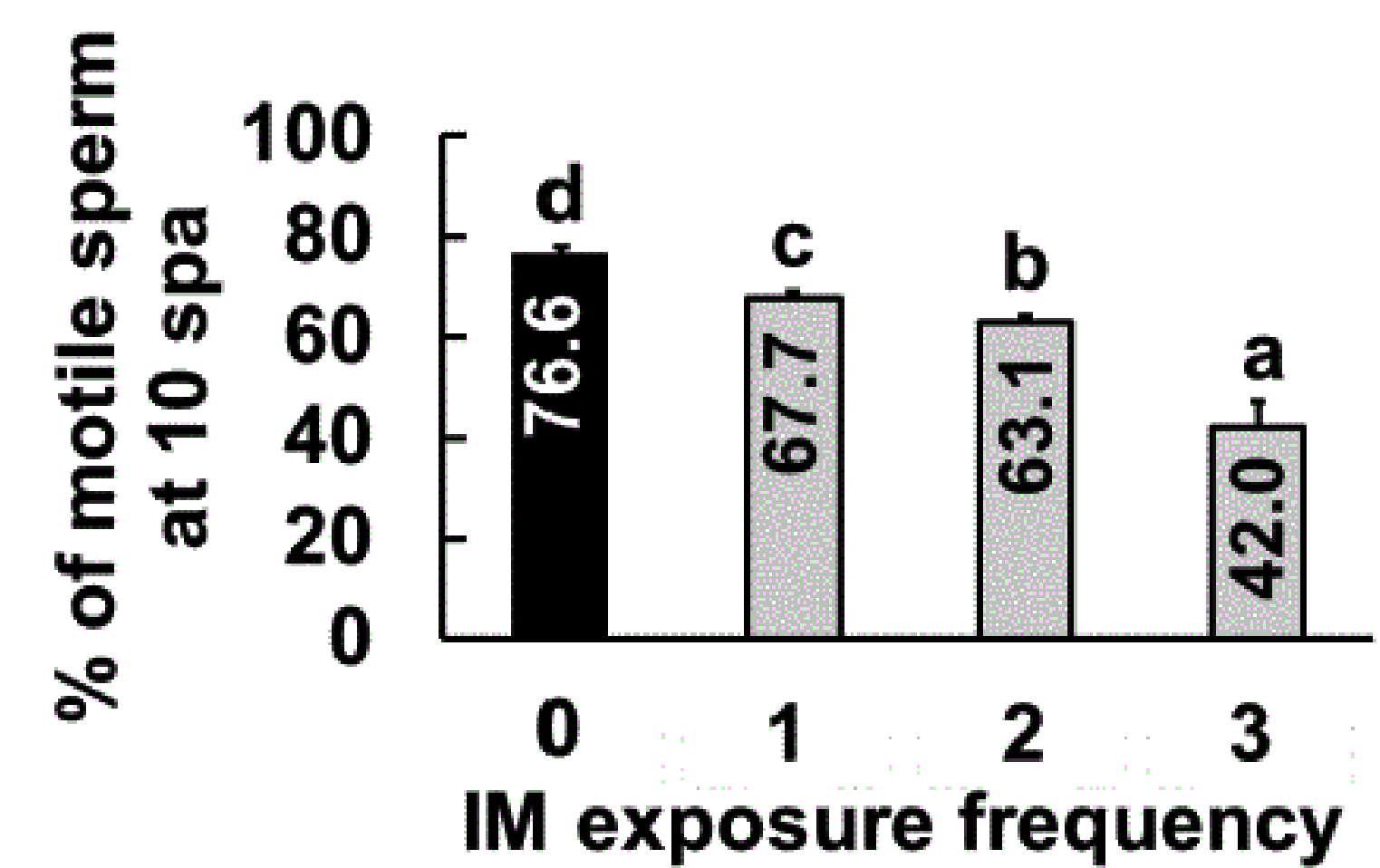

(f)

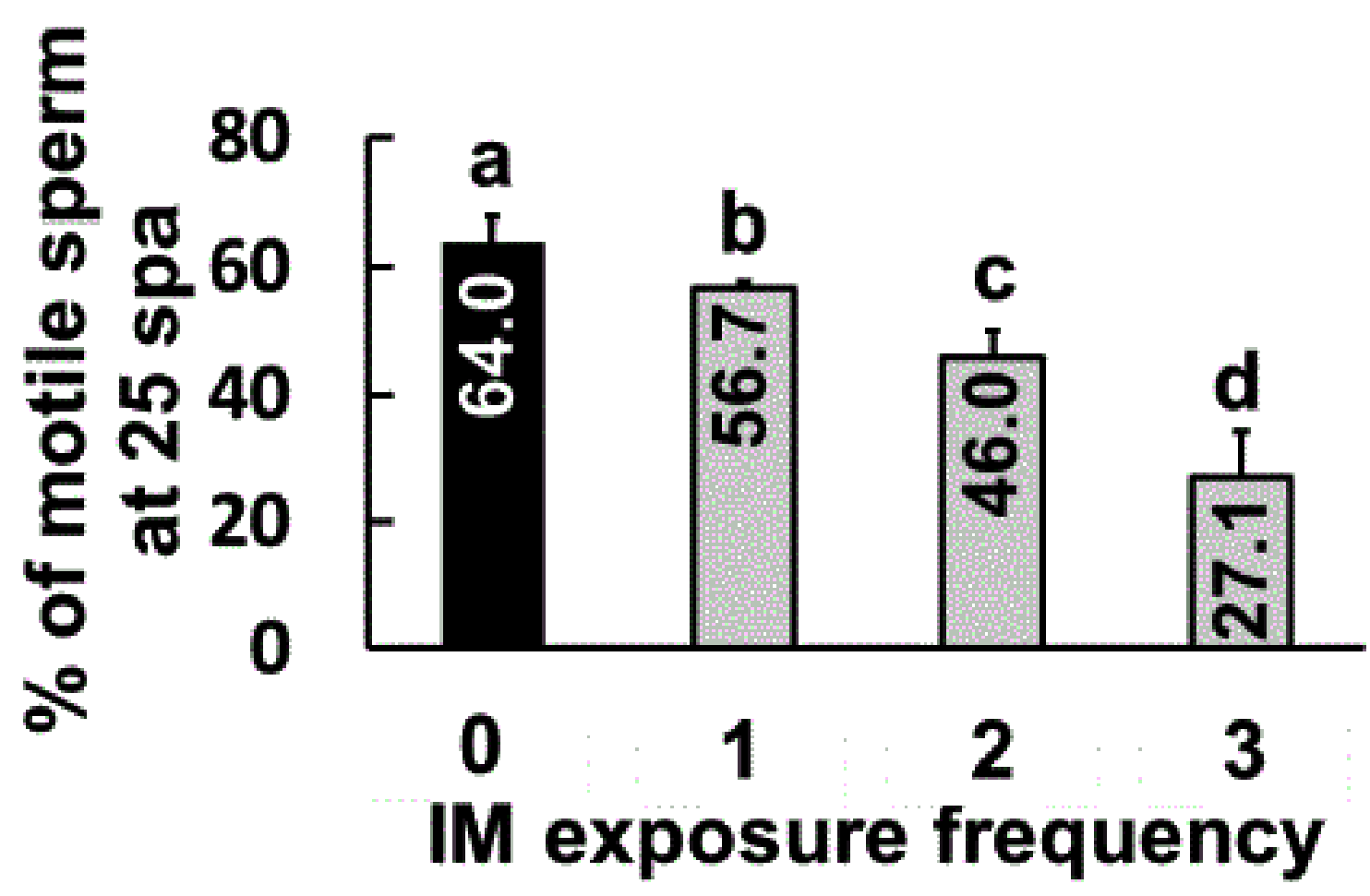

E

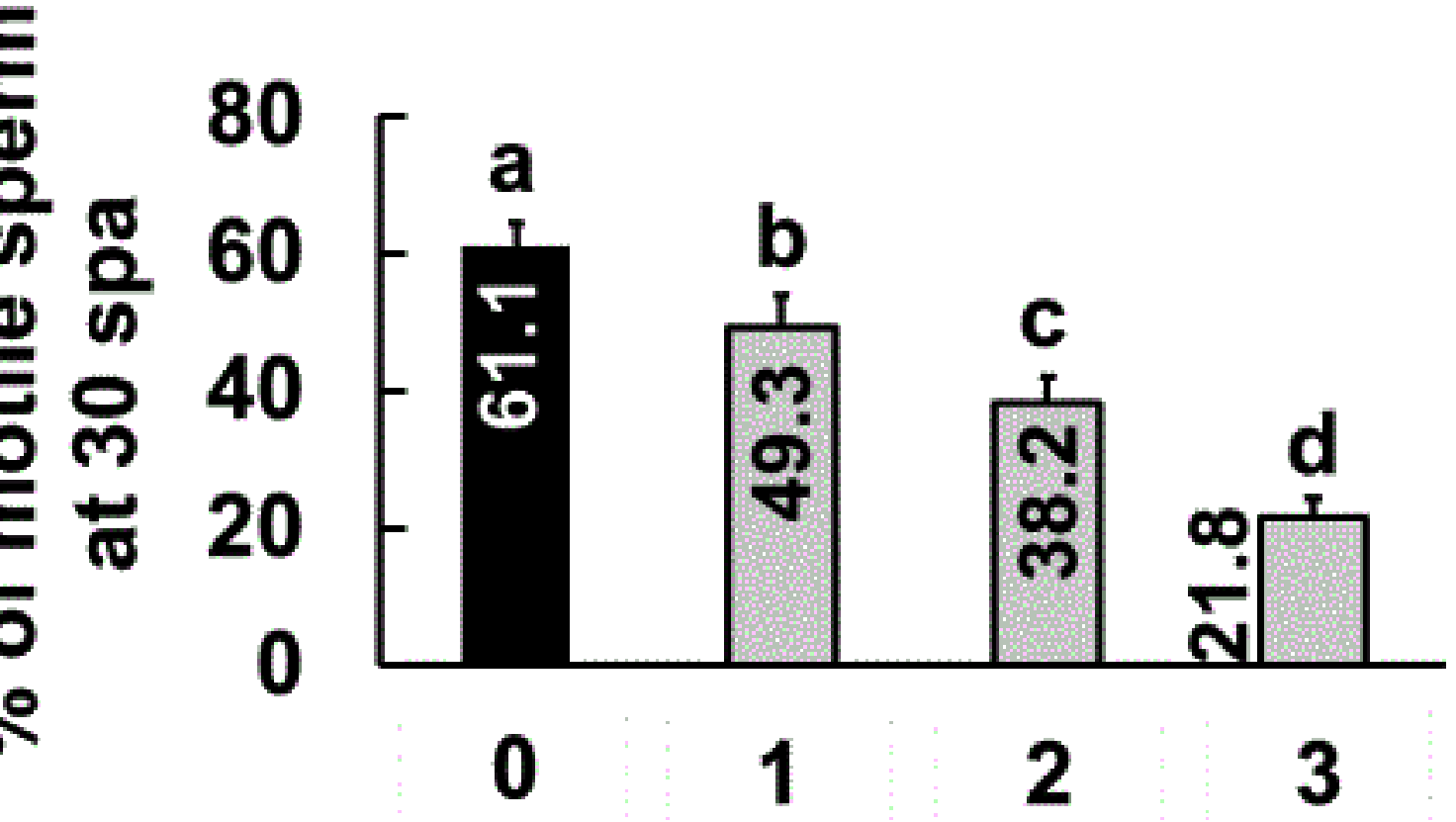

IM exposure frequency 


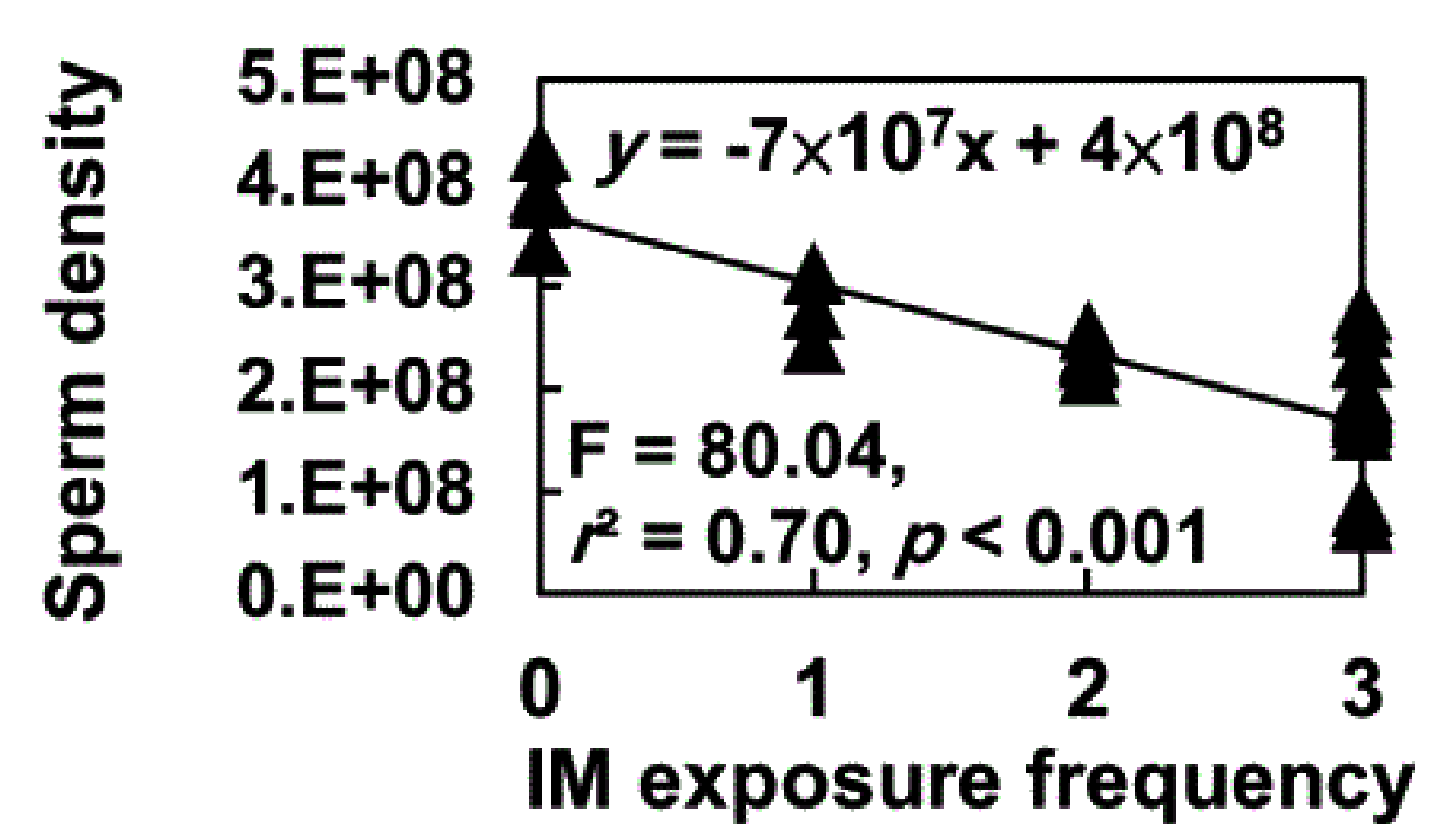

(d)

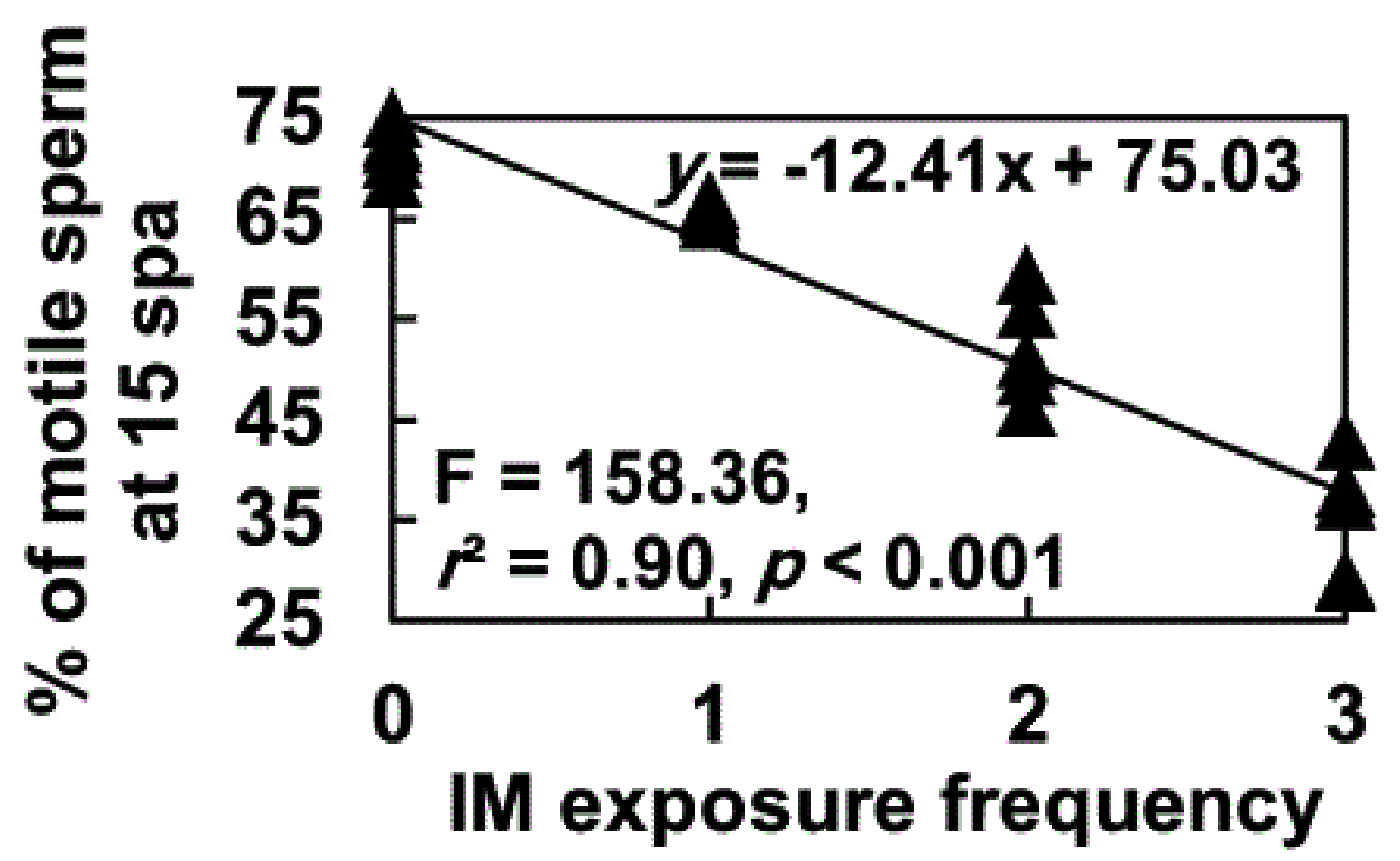

(g)

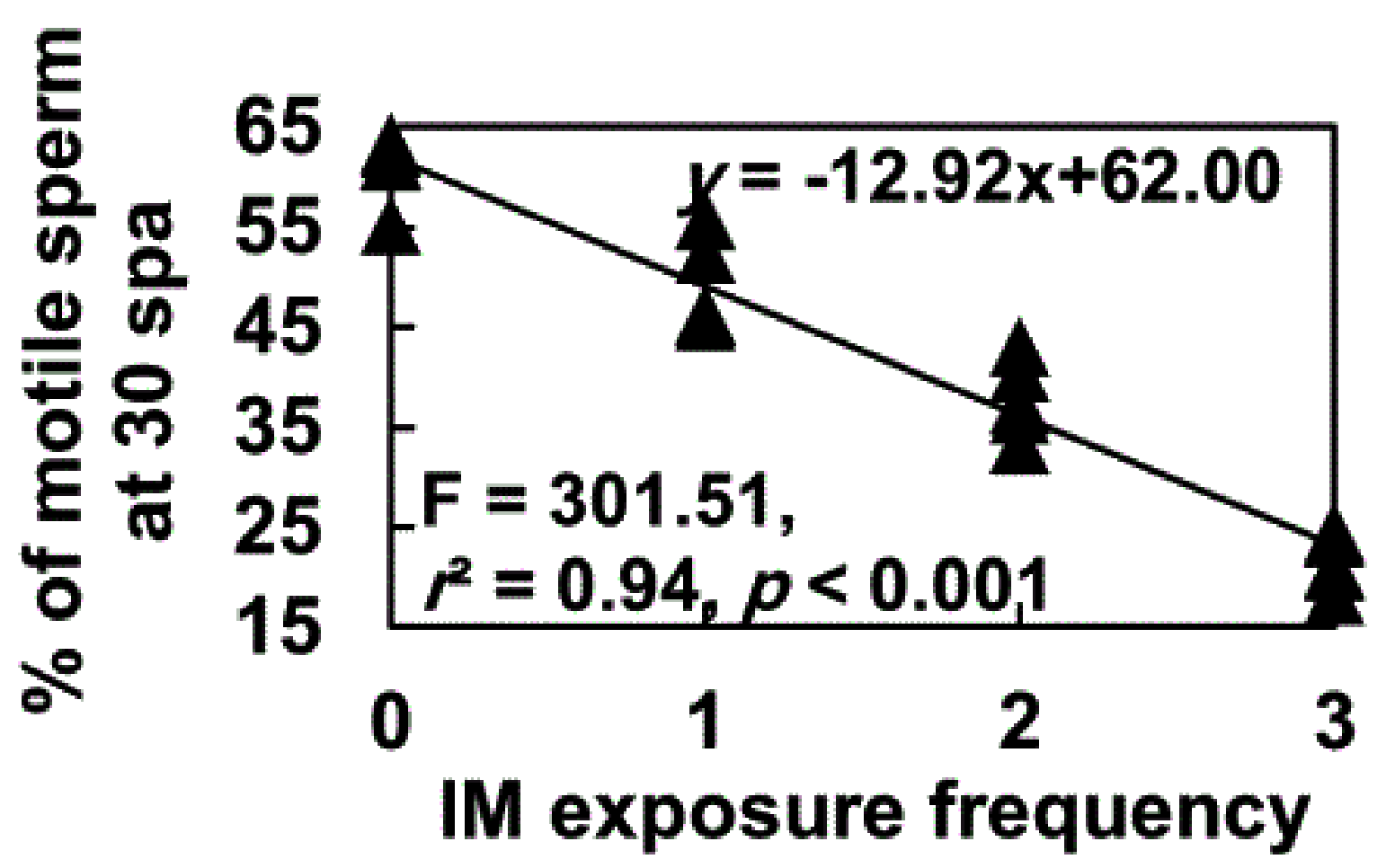

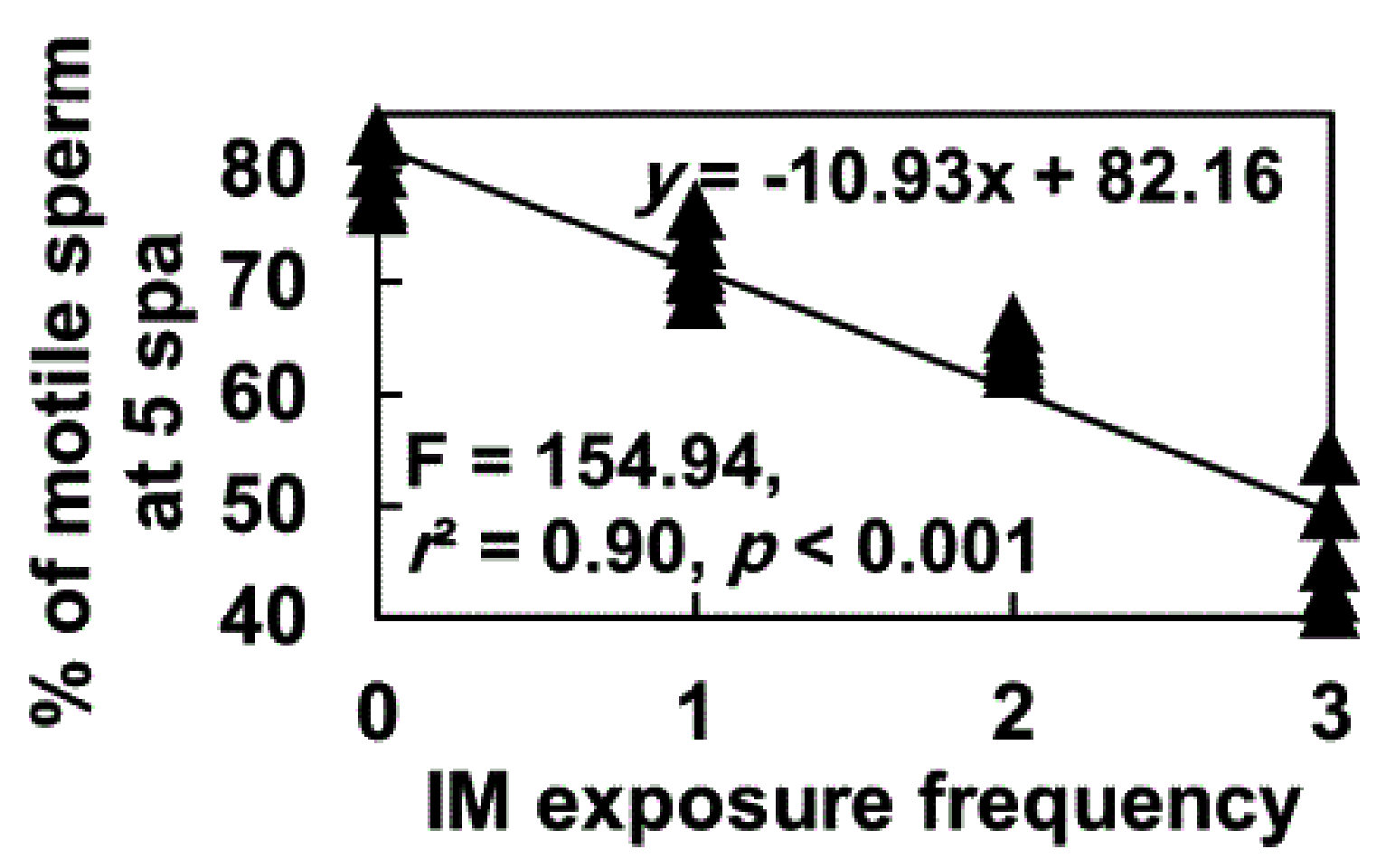

(e)

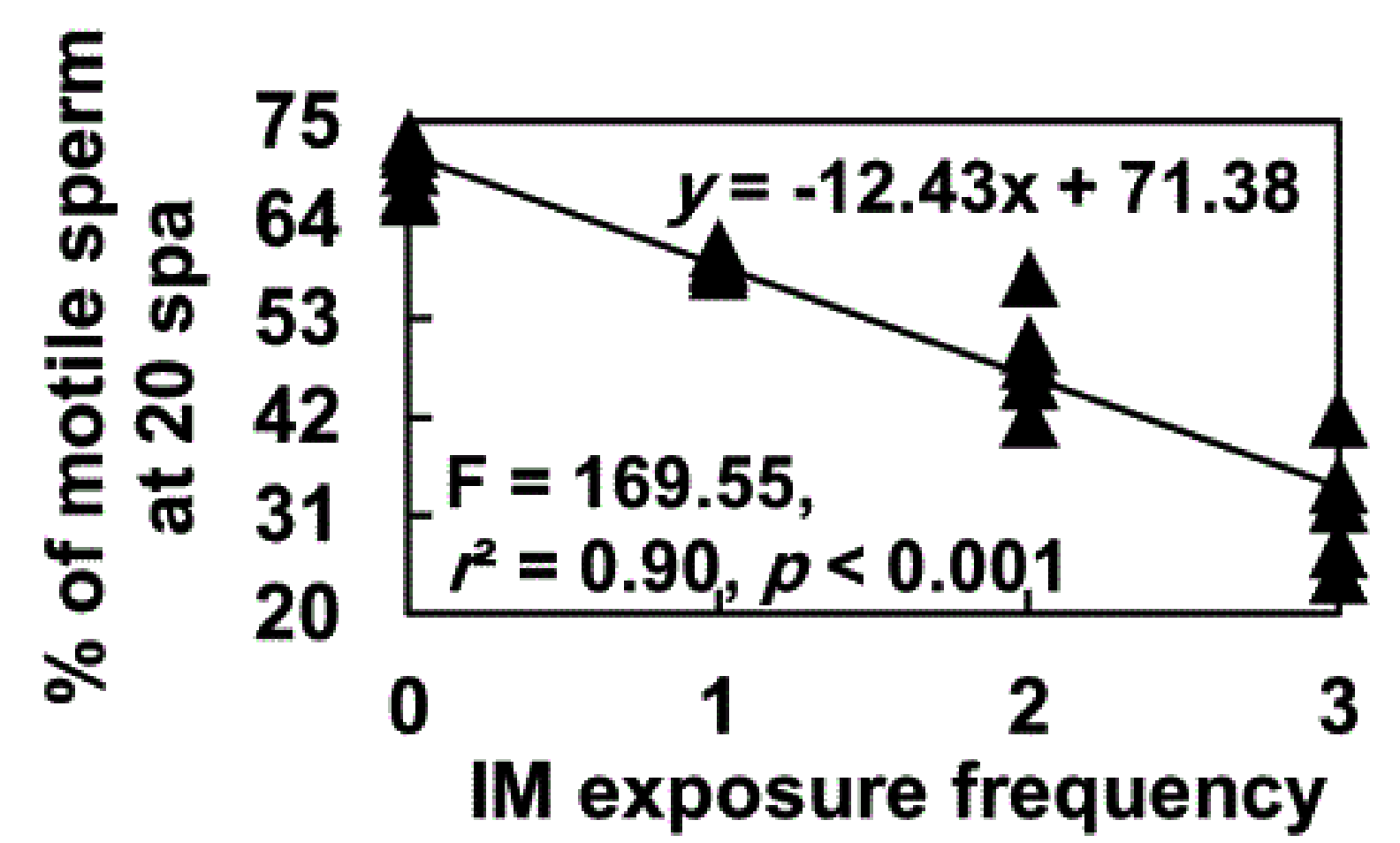

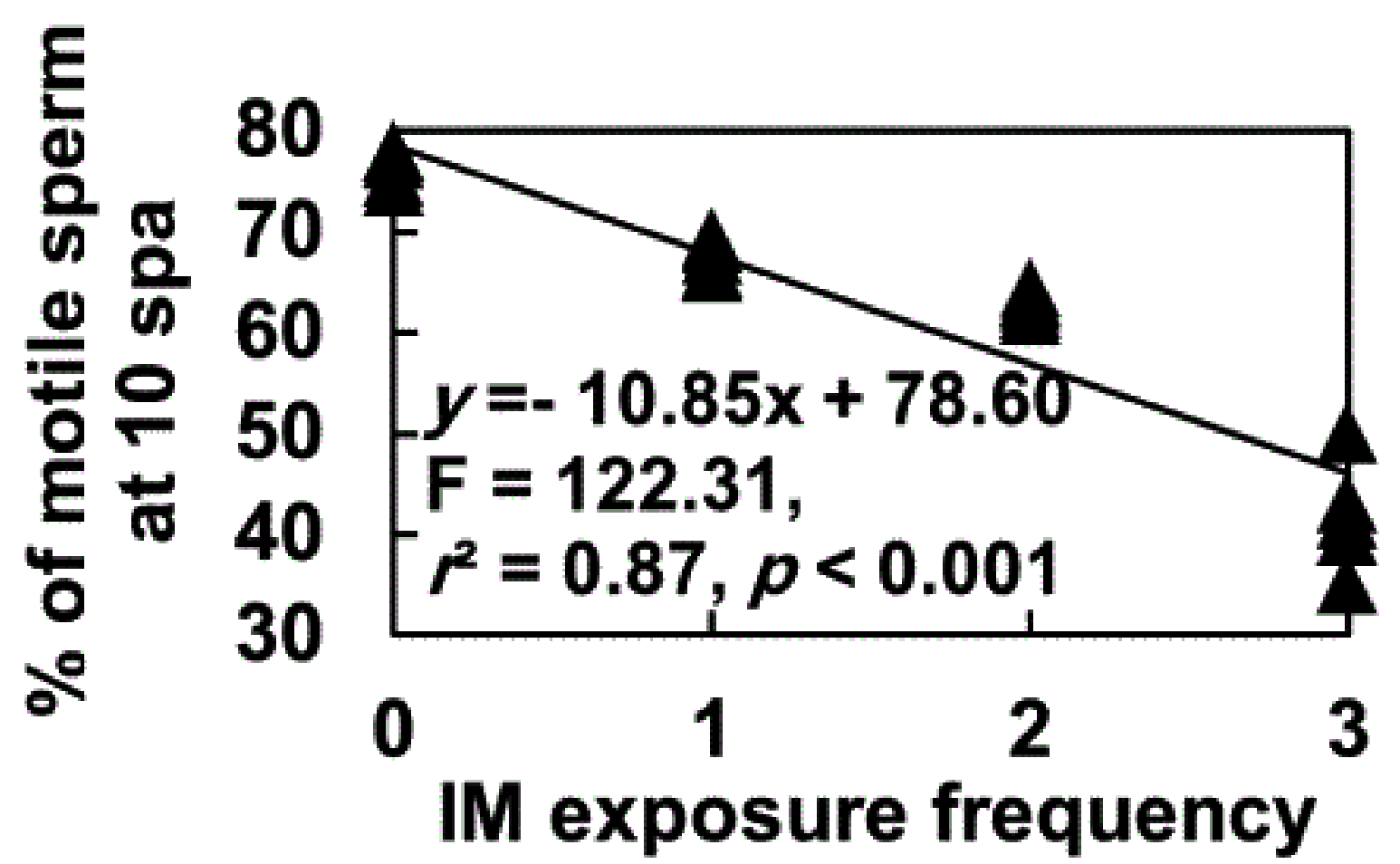

(f)

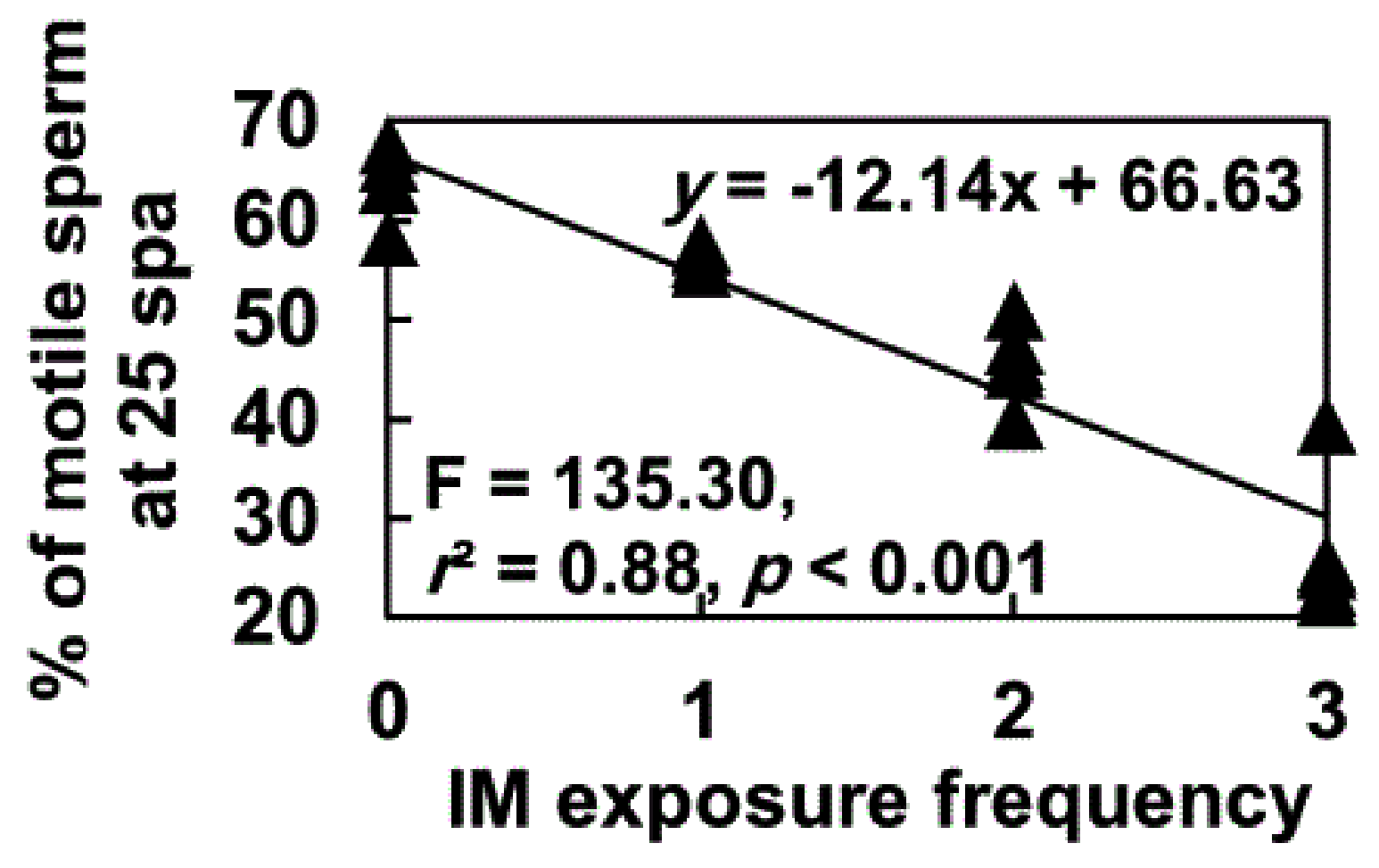

